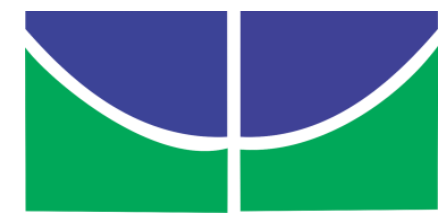

Universidade de Brasília - UnB

Instituto de Ciências Biológicas

Programa de Pós-Graduação em Zoologia

\title{
Isolamento reprodutivo em duas espécies simpátricas de Chinavia Orian (Hemiptera: \\ Pentatomidae): importância da comunicação vibracional e composição química da cutícula.
}

\author{
Samantha da Silveira \\ Orientador: Dr. Raúl Alberto Laumann \\ Co-orientadora: Dr. Maria Carolina Blassioli Morais
}

Brasília, 2015 
Universidade de Brasília - UnB

Instituto de Ciências Biológicas

Programa de Pós-Graduação em Zoologia

\title{
Isolamento reprodutivo em duas espécies simpátricas de Chinavia (Orian) (Hemiptera: Pentatomidae): importância da comunicação vibracional e composição química da cutícula.
}

\author{
Samantha da Silveira \\ Orientador: Dr. Raúl Alberto Laumann \\ Co-orientadora: Dra. Maria Carolina Blassioli Moraes
}

Dissertação apresentada ao Programa de Pós-graduação em Zoologia do Instituto de Ciências Biológicas da Universidade de Brasília (UnB), como requisito parcial à obtenção do grau de mestre em Zoologia.

Brasília, 2015 


\section{Agradecimentos}

Agradeço aos meus pais por todo amor e pelo intenso apoio e sempre presente incentivo aos meus estudos.

Ao meu amigo e marido, Fernando Vieira Barbosa, pela paciência infinita, por compreender os finais de semana sozinho, pelos conselhos, pelo imenso apoio e por não ter me deixado desistir quando tudo parecia dar errado.

Ao meu orientador Dr. Raúl A. Laumann que me ensinou muito mais que os procedimentos e conhecimento científico aplicados neste trabalho. Obrigada por toda paciência, compreensão, conselhos e companheirismo ao longo de todos esses anos;

À minha coorientadora Dra. Maria Carolina Blassioli Moraes que me auxiliou na extração e identificação dos compostos por GC-FID, GC-MS.

Ao Dr. Miguel Borges por toda colaboração e dicas baseada em toda sua carga científica.

Aos meus queridos amigos de laboratório, que sempre incentivaram a pesquisa e o crescimento profissional, pelas dicas, conversas científicas e conhecimentos compartilhados durante todo esse período. E por fazer o cotidiano em laboratório sempre divertido.

À minha amiga Aline Moreira Dias, pelo companheirismo, troca de informações e conhecimento científico. Pelas madrugadas de apoio e trocas de ideias aplicadas a este trabalho. Além da carona solidária diária e marmitas compradas.

À minha sogra, Edy das Graças Vieira, que ajudou como pôde, auxiliando diretamente nos cuidados domésticos.

À Universidade de Brasília (UnB), em especial ao Departamento de Pós-Graduação em Zoologia pela oportunidade de realização do mestrado;

À Embrapa Recursos Genéticos e Biotecnologia pela estrutura e apoio concedido ao longo da realização deste trabalho. 


\section{Índice}

Lista de Figuras e Tabelas ..................................................................................... 5

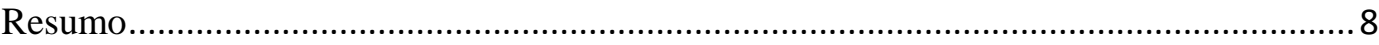

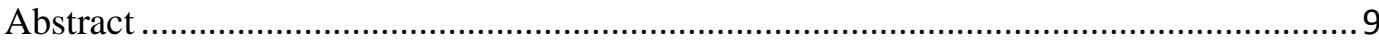

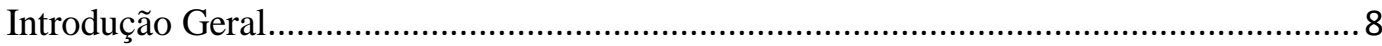

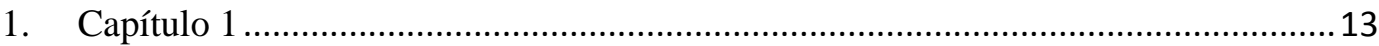

Resposta de machos de Chinavia ubica e Chinavia impicticornis (Hemiptera: Pentatomidae) a alterações nos cantos naturais de fêmeas coespecíficas. ......................... 13

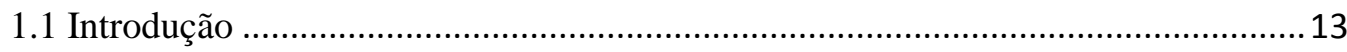

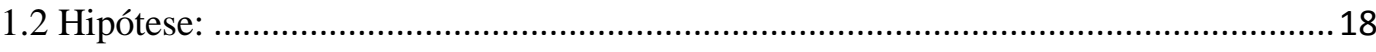

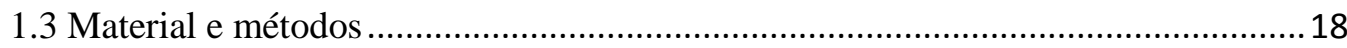

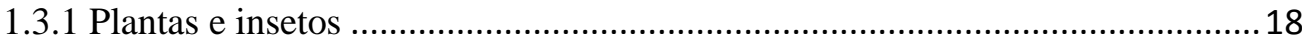

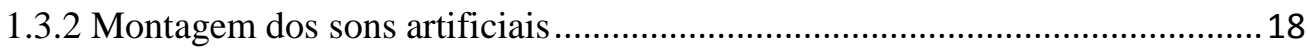

1.3.3 Reprodução dos sinais e resposta dos machos. ............................................... 20

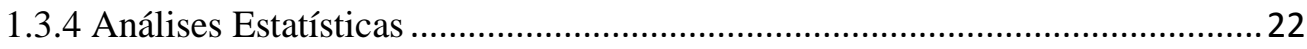

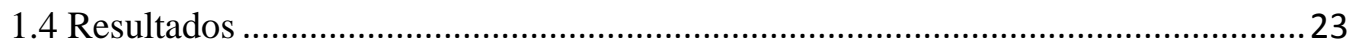

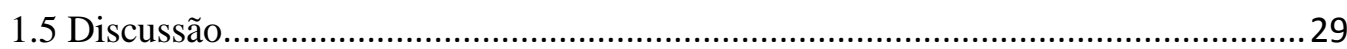

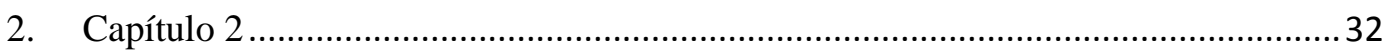

Identificação e comparação de hidrocarbonetos cuticulares presentes em Chinavia ubica e Chinavia impicticornis (Hemiptera: Pentatomidae)........................................................ 32

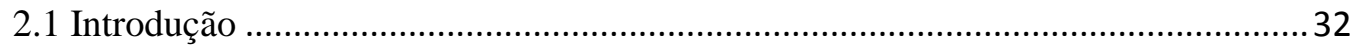

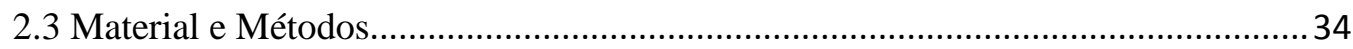

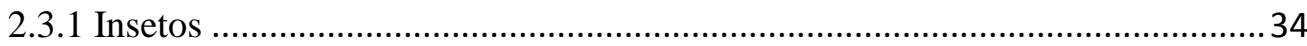

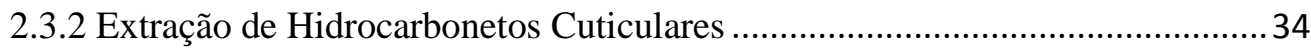

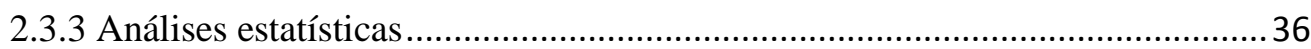

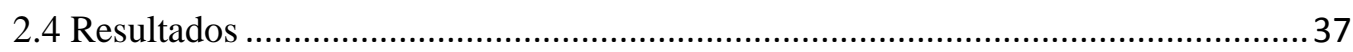

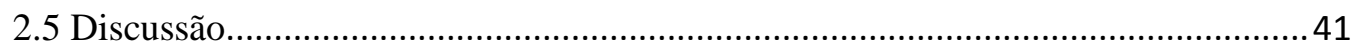

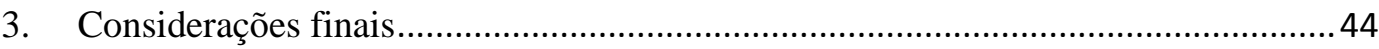

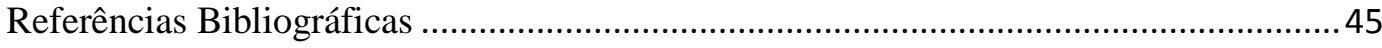




\section{Lista de Figuras e Tabelas}

Figura 1: Características temporais de um sinal vibracional de percevejos (adaptado de Čokl, 2008)

Figura 2: Especro característico de um sinal vibratório de percevejos mostrando os seus principais parâmetros (Adaptado de Čokl, 2008).

Figura 3: Comportamento de corte em Pentatomidae. Sequência de comportamento de corte de Nezara viridula. (Boges et al, 1987). 1: Aproximação do macho; 2, 3 :

Antenação; 4: Macho levanta o abdômen da fêmea; 5: Macho se direciona para a cópula;

6,7: Cópula; 8: Macho bate as asas.

Figura 4: Repertorio de sinais de Chinavia impicticornis e Chinavia ubica identificado por Laumann, Moraes e Borges (dados não publicados). FS-1a: canto 1 da fêmea (chamamento), FS-1b: canto 2 da fêmea (chamamento/dueto), MS-1: Canto 1 do macho (dueto), MS-2: canto 2 do macho, acasalamento/corte.

Figura 5: Esquema de oscilogramas representando os cantos montados artificialmente para Chinavia ubica (A) e Chinavia impicticornis (B). Natural (sinal emitido pelos insetos e registrado num alto falante); Sinal Artificial 1 com o mesmo tempo de duração do canto natural sem os pulsos adicionais (SA1); Sinal Artificial 2 com metade do tempo de duração do primeiro pulso com os pulsos adicionais (SA2); Sinal Artificial $3 \mathrm{com}$ metade do tempo de duração do primeiro pulso sem os pulsos adicionais (SA3); Sinal Artificial 4 com dobro do tempo de duração do primeiro pulso com os pulsos adicionais (SA4); Sinal Artificial 5 com o dobro do tempo de duração do primeiro pulso sem os pulsos adicionais (SA5).....

Figura 6: Representação esquemática da montagem dos experimentos com reprodução de sinais vibratórios utilizando um reprodutor eletromagnético (mini-shaker) e um acelerômetro para registro dos sinais emitidos pelos insetos avaliados.

Figura 7: Proporção de machos de C. ubica (A) e de C. impicticornis (B) que responderam aos sinais artificiais e que se orientaram em direção à fonte de emissão do sinal.

Figura 8: Tempo de latência e duração do canto de $C$. ubica (A) e $C$. impicticornis (B) em respostas aos sinais estímulo.Letras diferentes indicam respostas significativamente diferentes e as barras indicam o erro padrão.

Figura 9: Duração dos trens de pulsos de resposta, tempo de repetição, frequência dominante e proporção dos números de reposta em relação ao número de pulsos emitidos de C. ubica (A) e C. impicticornis (B) aos sinais artificiais. Os asteriscos indicam diferencias significativas nos valores dos parâmetros em relação ao sinal natural............28 Figura 10: Cromatograma representativo obtido a partir de amostras de extratos cuticulares de 20 fêmeas e machos de C. ubica.

Figura 11: Cromatógrama representativo obtido a partir de amostras de extratos cuticulares de 20 fêmeas e machos de C. impicticornis.

Figura 12: Quantidade total de hidrocarbonetos cuticulares em ng por inseto obtidas em amostras de pronoto e escutelo de fêmeas e machos C.ubica e C.impicticornis. As barras indicam o erro padrão.

Figura 13: Análise de variáveis canônicas (CVA) considerando fêmeas e machos de $C$. ubica e C. impicticornis como fator e os hidrocarbonetos cuticulares identificados em amostras de ambas as espécies-sexo. Os círculos representam os "scores" individuais 
para cada amostra (20 indivíduos de cada espécie e sexo) calculados a partir das equações da primeira e segunda variável canônica. As linhas representam as cargas ("loadings") para cada variável (composto) incluído na análise, a magnitude da linha representa a importância relativa de cada composto para diferenciar os tratamentos (espécie e sexo) nas duas dimensões do gráfico. 


\section{Lista de Tabelas}

Tabela 1: Características temporais dos sinais montados artificialmente 19

Tabela 2: Razão de probabilidades (Odd ratios) e IC 95\% para machos de $C$. ubica e $C$. impicticornis em resposta a sinais artificiais de fêmeas de cada espécie (FS1b) em relação aos sinais naturais. 24

Tabela 3 Hidrocarbonetos identificados em amostras de fêmeas e machos $C$. ubica e $C$. impicticornis. Com seus respectivos tempos de retenção e quantidades representados. Quantidade média ( $\mathrm{M} \pm \mathrm{DP}$ ), em ng/inseto, de cada amostra contendo 20 indivíduos. A identificação dos compostos foi obtida por análise em cromatógrafo gasoso (CG) acoplado a um espectrômetro de massas em coluna DB-5 


\section{Resumo}

Embora pouco conhecida, a emissão de sinais vibratórios através de substratos é uma modalidade de comunicação comum nos insetos. Muitos desses sinais são específicos e facilitam a localização do parceiro, reconhecimento e acasalamento. Assim como em outros pentatomídeos, as etapas reprodutivas de Chinavia ubica (Rolston, 1983) e Chinavia impicticornis (Stål, 1872) consistem em emissão de feromônio em longas distâncias, além de sinais vibracionais e toque com as antenas (antenação) em curtas distâncias. Este trabalho foi orientado a estabelecer se diferenças nas características temporais dos sinais vibracionais de ambas as espécies induzem variação na resposta dos indivíduos a fim de estabelecer se a especificidade da comunicação vibracional está relacionada à composição temporal dos sinais vibratórios. Adicionalmente estudo-se a composição química da cutícula dessas duas espécies para estabelecer se existem diferencias a nível específico e entre os sexos que possam sugerir uso destes compostos para reconhecimento e discriminação entre os indivíduos na fase de corte do comportamento reprodutivo. Verificou-se que alteração dos parâmetros temporais dos sinais vibratórios das fêmeas de ambas as espécies em relação aos sinais naturais diminuem a resposta dos machos coespecíficos comprovando a hipótese que o reconhecimento e discriminação dos sinais vibratórios estão relacionados a parâmetros temporais espécie específicos. Ambas as espécies mostraram possuir perfis de hidrocarbonetos cuticulares similares com diferencias entre espécies e sexos o que sugere a sua possível função como sinais químicos utilizados durante o comportamento de corte. Os resultados deste trabalho mostraram que o isolamento reprodutivo das espécies simpátricas de Chinavia estudadas é uma consequência de um sistema de sinalização multimodal que inclui alem dos feromônios sexuais, previamente identificados, sinais vibratórios e sinais químicos não voláteis (hidrocarbonetos cuticulares).

Palavras chave: Chinavia ubica, Chinavia impicticornis, sinais, comunicação química, hidrocarbonetos cuticulares, discriminação interespecífica. 


\begin{abstract}
Though little known, the issue of vibratory signals through substrates is a common form of communication in insects. Many of these signs are specific and facilitate the partner's location, recognition and mating. As in other pentatomids, reproductive stages of Chinavia ubica (Rolston, 1983) e Chinavia impicticornis (Stål, 1872) consist of pheromone emission over long distances, and vibrational signals and touch the antennas (antennation) over short distances. This study was directed to determining whether differences in the temporal characteristics of the vibrational signals of both species induce variation in the response of individuals to establish the specificity of vibrational communication is related to the temporal composition of vibratory signals. Additionally study up the cuticle of the chemical composition of these two species to establish whether the specific differences within and between the sexes that may suggest use of these compounds for recognition and discrimination among individuals in cutting phase of reproductive behavior. It was found that alteration of temporal parameters of the vibratory signals of females of both species in relation to the natural decreasing the response signals of conspecific males, support the hypothesis that the recognition and discrimination of vibration signals are related to specific temporal parameters species. Both species have similar profiles cuticular hydrocarbons with differences between species and sex suggesting its possible role as chemical signals used during cutting behavior. These results show that reproductive isolation of simpatric Chinavia species studied is a result of a multimodal signaling system which includes addition of sex pheromones, previously identified, vibrational signals and non-volatile chemical signals (cuticular hydrocarbons).
\end{abstract}

Key words: Chinavia ubica e Chinavia impicticornis, Chinavia ubica, signals, chemical communication, cuticular hidrocarbons, interespecific discrimination. 


\section{Introdução Geral}

Dentre as subfamílias de Pentatomidae, Pentatominae é a maior delas. Dos cerca de 36.096 espécies descritas de Heteroptera, 4.123 espécies pertencem à família Pentatomidae e é classificada como a terceira maior família juntamente com o Lygaeidae. (Panizzi et al., 2000). Seus membros, os percevejos fitófagos, são caracterizados por possuírem cinco segmentos nas antenas, três segmentos tarsais e um escutelo pequeno e triangular.

Alimentam-se inserindo o estilete na planta e sugando seus nutrientes, atacando, geralmente, seus órgãos reprodutivos, causando assim injurias nos tecidos vegetais e abrindo uma porta de entrada para patógenos causadores de doenças (Panizzi et al., 1997). Além disso, podem levar à murcha e aborto dos frutos e sementes. Por se alimentarem de espécies de plantas de valor econômico, muitas espécies são consideradas pragas agrícolas (Panizzi et al., 2000).

No Brasil os percevejos ocorrem do Norte ao Sul (Corrêa-Ferreira \& Panizzi, 1999) e várias espécies têm sido registradas como pragas agrícolas principalmente de leguminosas e outros grãos, em particular, a cultura de soja, onde percevejos da família Pentatomidae são considerados pragas principais. Estes insetos atacam a planta desde o florescimento até a maturidade fisiológica (Panizzi \& Vivan, 1997), sendo responsáveis por danos diretos à cultura causando redução da produção e perda na qualidade das sementes (Belorte et al., 2003). Nesta cultura os percevejos são encontrados em um complexo de espécies que varia em composição e abundância de acordo com a região produtora, sendo Nezara viridula Linneaus, 1758, Piezodorus guildinii Westwood,1837, Euschistus heros Fabricius,1794 as pragas de maior impacto econômico na produção de soja brasileira (Belorte et al., 2003). Além dessas, existem outras espécies, como as do gênero Chinavia Orion que ocorrem com menor frequência (Schwernter \& Grazia, 2006).

A importância dos percevejos para a cultura da soja se manifesta ao considerar que o Brasil é o segundo maior produtor mundial de soja. Para o ano de 2015 estima-se uma produção de 95,92 milhões de toneladas, $11,4 \%$ superior as 86,12 milhões de toneladas colhidas em 2013/14 (Conab, 2015).

O principal método de controle dos percevejos é realizado através da aplicação de defensivos agrícolas nas plantações. Sendo comercializadas, somente no Brasil em 2011, 826.683 toneladas, acréscimo de 4,9\% em relação a 2010 (Ferreira et al., 2012). O uso indiscriminado destes produtos pode levar ao surgimento de populações resistentes 
gerando a perda da eficiência do produto, contaminação do solo e lençóis freáticos e efeitos nocivos à fauna benéfica. Além de afetar a saúde dos trabalhadores rurais. Assim a busca por métodos alternativos de controle surge como uma necessidade prioritária, entre estes métodos a manipulação comportamental apresenta grande potencial. Sinais utilizados pelos insetos para se comunicarem podem ser, uma vez identificados, utilizados para atraí-los, dispersá-los ou ainda interferir nesta comunicação utilizando sinais de interferência ou disrupção.

O comportamento reprodutivo de percevejos é complexo e envolve a produção de sinais específicos que garantem a comunicação dos indivíduos. Dentre esses sinais destacam-se os feromônios sexuais. Esses feromônios, produzidos pelos machos, são um meio de comunicação quando os insetos se encontram em distâncias maiores, e o primeiro passo para a formação das duplas para a cópula já que atuam como atrativos para as fêmeas (Moraes, 2008; 2005, Borges et al., 2006; Borges et al., 2007).

A composição química dos feromônios de algumas espécies de percevejos no Brasil foram identificados. Dentre eles Euschistus heros (Fabricius, 1974), Edessa meditabunda (Fabricius, 1974), Piezodorus guildinii (Westwood, 1837), Thyanta perditor (Fabricius, 1974), Chinavia ubica (Rolston, 1983) e Chinavia impicticornis (Stål, 1872), Oebalus poecilus (Dallas, 1851), Tibraca limbativentris (Stål, 1872), Nezara viridula (Linnaeus, 1758), Pallantia macunaina (Grazia, 1980) e Agroecus griséus (Dallas, 1851) (Zhang et al., 2003., Zarbin et al., 2000; 2012, Moraes et al., 2005; 2012, Moraes et al., 2013; Borges et al., 2006, 2007, Fávaro et al., 2012). Todos os trabalhos citados acima confirmaram a alta especificidade das moléculas feromonais envolvidas na comunicação química dos percevejos.

Após as fêmeas serem atraídas para as plantas onde se encontram os machos, são elas as responsáveis pelo início da emissão dos sinais vibratórios que atraem o sexo oposto durante a corte inicial (Borges et al., 1987; Čokl et al., 2000a; Moraes et al., 2005). A função da comunicação vibracional é a de troca de informações entre os indivíduos durante a etapa reprodutiva, quando estes estão separados por distâncias moderadas ou curtas (poucos metros a alguns centímetros).

$\mathrm{Na}$ etapa final do comportamento reprodutivo dos percevejos (quando os insetos estão a distâncias que permitem o contato físico) sinais visuais, físicos e químicos são importantes para o reconhecimento e finalmente predispor os insetos para a cópula (Borges et al., 1987; Laumann et al., 2013). Nesta etapa os insetos desenvolvem 
movimentos estereotipados e uma intensiva prospecção do corpo do parceiro utilizando as antenas (antenação) (Borges et al., 1987).

O uso de feromônios para atração para armadilhas é uma técnica amplamente utilizada para manejo de insetos praga. No caso de percevejos vários estudos demonstraram a potencialidade desta técnica para o monitoramento populacional (Borges et al., 1998a, 1998b, 2011, Millar et al., 2002, Pires et al., 2006, Laumann et al., 2011). A técnica de monitoramento com armadilhas de feromônio é especialmente útil para identificar a infestação inicial das culturas e os picos populacionais, permitindo que as aplicações de medidas de controle sejam realizadas no momento mais adequado aumentando assim a sua eficiência (Borges et al., 2011). O uso de sinais vibratórios pode ser um complemento ao uso de feromônios (Čokl \& Millar, 2009). O desenvolvimento de armadilhas com sinais químicos (feromônios) e vibratórios pode originar uma ferramenta mais eficaz ao controle da praga por conter todos os sinais utilizados pelos insetos durante seu comportamento reprodutivo.

Chinavia ubica e Chinavia impicticornis possuem ampla distribuição em todo Brasil e estão associadas a plantas como soja (Glycine max L.) e feijão (Phaseolus vulgaris L.) (Schwertner \& Grazia, 2007). Nestas plantas as duas espécies sobrevivem e se reproduzem confirmando seu hábito alimentar polífago (Schwertner \& Grazia, 2007). Segundo SILVA et al. (2015), os adultos de C. ubica e C. impicticornis possuem altas taxas de longevidade e fecundidade, o que poderia permitir crescimentos explosivos das populações nas culturas agrícolas tornando-as pragas potenciais para a soja.

Atualmente o gênero Chinavia (Orian) contém 80 espécies descritas, distribuídas nas Regiões Afrotropical, Neártica e Neotropical, destas, 32 ocorrem no Brasil (Schwertner \& Grazia, 2006). Dentre elas, 18 espécies de Chinavia foram registradas associadas a 55 espécies de plantas de 24 famílias (Schwertner \& Grazia, 2007). De modo geral, as espécies do gênero Chinavia são polífagas e consideradas pragas secundárias, porém, as áreas cultivadas durante o ano todo, com a expansão do sistema de semeadura direta e da safrinha de milho, fornecem condições ideais para a sobrevivência de insetos polífagos, cuja população pode aumentar a ponto de causar danos significativos. Além disso, seus danos somam-se aos das espécies principais (E. heros, N. viridula e $P$. guildinii), agravando os prejuízos (Panizzi et al., 2013).

Assim como em outros pentatomídeos, os machos de C. ubica e C. impicticornis produzem o feromônio sexual (Blassioli-Moraes et al., 2012). O feromônio de ambas as espécies possui os mesmos componentes ( $\alpha$ - bisaboleno e trans-(Z)-(4S) bisaboleno 
epoxide), sendo que $C$. ubica possui um composto específico a mais (cis-(Z)-(4S) bisaboleno epoxide) que o feromônio emitido por C. impicticornis. Estes compostos foram identificados também como componentes do feromônio sexual de outra espécie filogeneticamente relacionada, Nezara viridula, (Baker et al., 1987), o que sugere que a especificidade na comunicação química logra-se através de diferentes combinações e proporções dos compostos nas misturas feromonais (Moraes et al., 2008).

Além da emissão de feromônios, essas duas espécies apresentam comunicação vibracional (Lopes et al., 2006). Observou-se que, após a fêmea emitir sinais vibratórios, os machos coespecíficos respondem com sinais específicos. Após a formação de duetos o macho se movimenta em direção à fêmea e, uma vez em contato físico os insetos se tocam com as antenas e caso aceitem o parceiro o comportamento finaliza com a cópula (McBrien et al., 2005, Borges et al., 1987, Moraes et al., 2005, Moraes et al., 2013)

Estudos complementares sobre a comunicação vibracional das espécies praga deste grupo em questão são necessários para entender seu comportamento e compreender melhor todas as etapas da comunicação entre os indivíduos. Quanto mais refinada a compreensão do seu comportamento, haverá maiores possibilidades de desenvolvimento de métodos alternativos para manejo e controle destes insetos com os consequentes benefícios ambientais, econômicos e sociais.

Por exemplo, o uso de feromônios para atração para armadilhas é uma técnica amplamente utilizada para manejo de insetos praga. No caso de percevejos vários estudos demonstraram a potencialidade desta técnica para o monitoramento populacional (Borges et al., 1998a, 1998b, 2011, Millar et al., 2002, Pires et al., 2006, Laumann et al., 2011). A técnica de monitoramento com armadilhas de feromônio é especialmente útil para identificar a infestação inicial das culturas e os picos populacionais, permitindo que as aplicações de medidas de controle sejam realizadas no momento mais adequado aumentando assim a sua eficiência (Borges et al., 2011). O uso de sinais vibratórios pode ser um complemento ao uso de feromônios (Čokl \& Millar, 2009). O desenvolvimento de armadilhas com sinais químicos (feromônios) e vibratórios pode originar uma ferramenta mais eficaz ao controle da praga por conter todos os sinais utilizados pelos insetos durante seu comportamento reprodutivo.

No capítulo 1 deste trabalho será abordado um estudo do comportamento vibracional de Chinavia ubica e Chinavia impicticornis (Hemiptera: Pentatomidae) avaliando a importância das características temporais de cada canto na comunicação nas duas espécies, avaliou-se se variações na estrutura temporal dos sinais vibratórios 
interferem na identificação e resposta das fêmeas de cada espécie. No capítulo 2 avaliouse a composição de hidrocarbonetos cuticulares de cada espécie e sexo visando estabelecer possíveis diferencias que indiquem a relevância destes compostos na comunicação química e isolamento reprodutivo destas espécies. 


\section{Capítulo 1}

\section{Resposta de machos de Chinavia ubica e Chinavia impicticornis (Hemiptera: Pentatomidae) a alterações nos cantos naturais de fêmeas coespecíficas.}

\subsection{Introdução}

A comunicação medeia a maioria dos comportamentos em animais e é determinante para a sua reprodução e sobrevivência (McGregor, 2005 in Žunic et al., 2011). A comunicação pode ser definida como o intercâmbio de informação entre indivíduos onde tanto o emissor quanto o receptor se beneficiam (em termos adaptativos) com esta troca (Greenfield et al., 2002). Os sinais são modificações do ambiente físico ou químico induzidas pelos sinalizadores (emissores) mediante comportamentos específicos que são utilizados pelos receptores para obter informação a respeito da identidade, condição fisiológica ou comportamental ou qualquer outra informação que o próprio emissor tenha recebido e processado previamente (ex. localização de uma fonte de alimento) (Greenfield et al., 2002; Scott-Phillips, 2008). Nos insetos têm evoluído complexos sistemas de comunicação mediante o uso de diferentes tipos de sinais, destes os mais conspícuos e estudados são sinais sonoros e sinais químicos. Entretanto existem outros tipos de sinais que por terem sido menos estudado ou por serem pouco evidentes são menos conhecidos, como os sinais vibratórios.

A emissão de sinais vibratórios através de substratos pelos insetos já é conhecida há muito tempo (início da década de 1960). Posteriormente percebeu-se que esses sinais poderiam ter uma importante função desencadeando ou modulando comportamentos dos insetos (Čokl \& Virant-Doberlet, 2003) e se comprovou a universalidade deste tipo de comunicação.

A comunicação vibracional foi relatada em 14 das 31 Ordens conhecidas de insetos (Virant-Doberlet \& Čokl, 2004; Crocroft \& Rodríguez, 2005). É estimado que 150 mil espécies descritas de insetos se comunicam exclusivamente por sinais vibracionais e que talvez outras 45 mil espécies usem esse tipo de comunicação juntamente com outros métodos de sinalização (Crocroft \& Rodríguez, 2005). Estas vibrações podem fornecer informação de identidade específica e outras informações como localização espacial, disponibilidade para a cópula e informações envolvidas em interações sociais (Crocroft \& Rodríguez, 2003; Hill, 2009). A evolução da capacidade de gerar sinais mediante 
intrincados padrões de vibração no substrato permitiu a comunicação com os coespecíficos, mediante sinais pouco conspícuos, o que teria a vantagem de mantê-los isolados de predadores e competidores (Hill, 2008 in Cocroft, 2011).

Entre os insetos que se comunicam através de sinais vibratórios encontram-se os percevejos (Heteroptera: Pentatomidae). Neste grupo os sinais são produzidos pela vibração dos primeiros escleritos abdominais, movimentados por músculos especiais. Esta vibração se transmite através das patas, que atuam como "molas" (Čok1 \& VirantDoberlet, 2003), para propagar o sinal através das plantas (Michelsen et al., 1982). Os sinais gerados por este mecanismo são de baixa frequência, na faixa de 50 a $200 \mathrm{~Hz}$, com a maior parte dos sinais ficando em torno de $100 \mathrm{~Hz}$ (Čokl \& Virant-Doberlet, 2003). Sinais emitidos nessa faixa de frequência estão finamente relacionados com as características físicas e mecânicas dos tecidos das plantas, o que facilita sua transmissão à distância (Miklas et al., 2001; Čok1, 2008).

Através dos sinais vibratórios os percevejos recebem e enviam informações de localização, sexo do indivíduo e receptividade para a cópula (Virant-Doberlet \& Čokl, 2004). Por exemplo, o repertório de canções do percevejo verde, Nezara viridula, consiste em sinais de chamamento, corte e rivalidade entre machos (Čokl et al., 2000a). Cada canção tem parâmetros temporais como duração do trem de pulso, intervalo entre trens de pulso, tempo de repetição e duty cycle ou ciclo de trabalho (Figura 1) e espectrais como frequência dominante, amplitude de banda, presença de harmônicos (Figura 2) específicos que permitem caracterizá-las e conferem especificidade (Čokl et al., 2000b).

Chinavia ubica e Chinavia impicticornis também utilizam a comunicação vibracional durante as etapas da reprodução, estes sinais possuem características que permitem diferenciar claramente os sinais emitidos por indivíduos, machos ou fêmeas, de cada espécie (Moraes et al., 2005; Laumann, R., Blassioli-Moraes, M.C., Borges, M., dados não publicados). Quando pares de fêmea-macho heteroespecíficos foram colocados na arena, apenas $60 \%$ das fêmeas emitiram a canção de chamamento e menos da metade dos machos responderam com a canção de acasalamento. Dentre esses pares que responderam nenhum deles concluiu com a cópula (Laumann, R., Blassioli-Moraes, M.C., Borges, M., dados não publicados). 


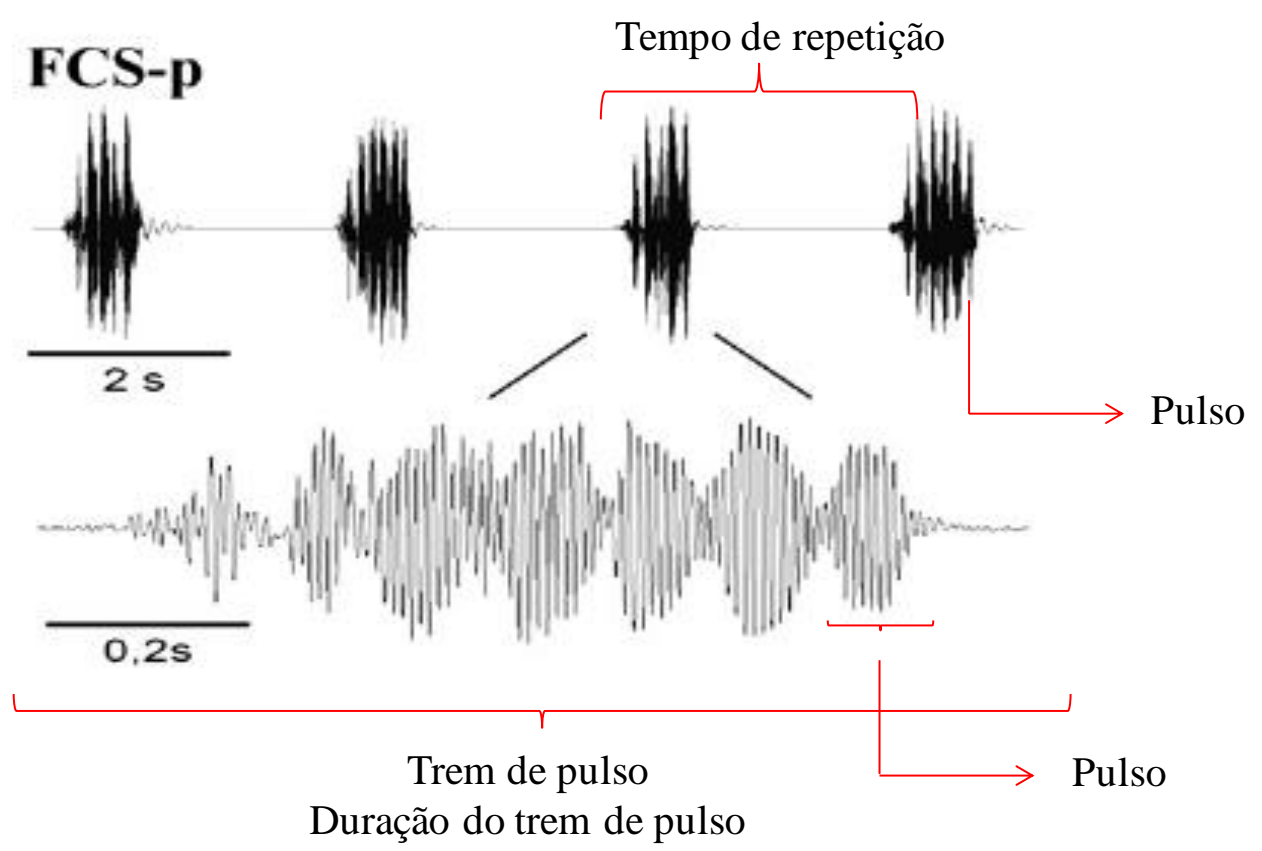

Figura 1: Características temporais de um sinal vibracional de percevejos (adaptado de Čokl, 2008).

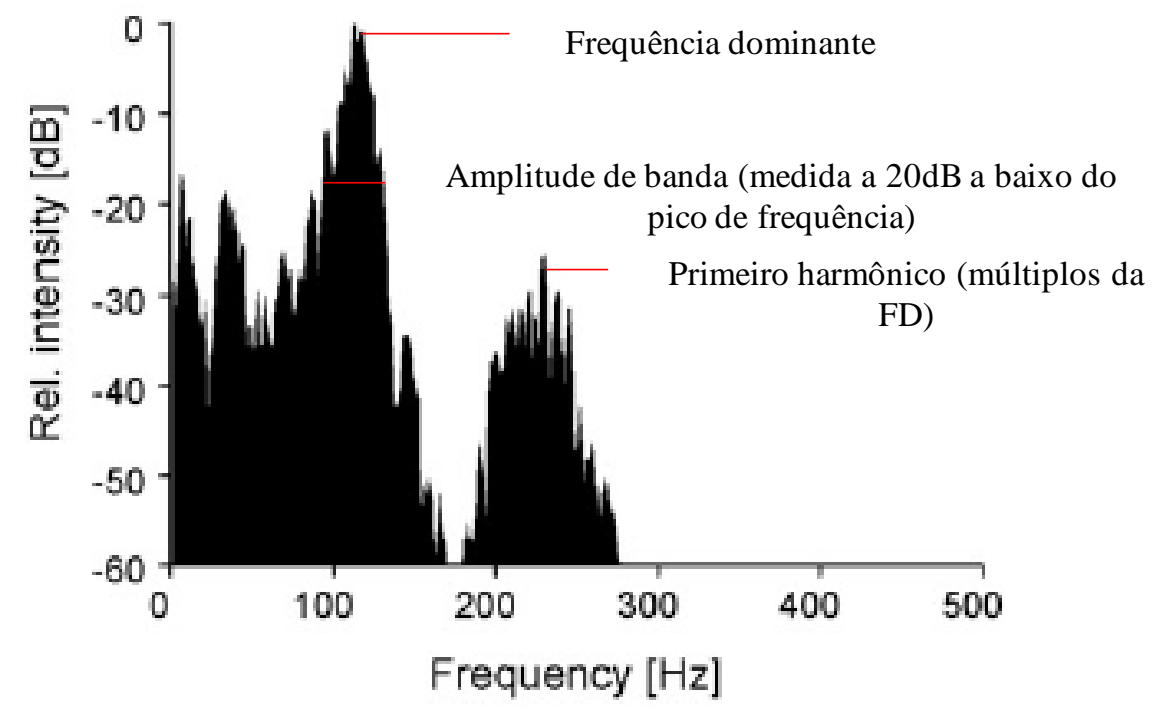

Figura 2: Especro característico de um sinal vibratório de percevejos mostrando os seus principais parâmetros (Adaptado de Čokl, 2008).

Nestas espécies tanto machos quanto fêmeas emitem dois tipos de sinais vibratórios. O repertório se inicia com o canto de chamamento da fêmea (identificado como FS-1a; Figura 3 e 4) que serve para que o macho identifique o posicionamento da fêmea na planta e estimule a emissão do canto inicial do macho (MS1). Após a resposta dos machos, a fêmea muda seu canto para o canto FS-1b e se inicia uma etapa onde os insetos cantam em dueto. Posteriormente quando os insetos estão em contato físico os machos emitem o canto de acasalamento (MS2; Figura 3 e 4) que silencia a fêmea e se 
inicia o ritual de acasalamento que finaliza com a cópula (Figura 3) (Moraes et al., 2005, Laumann, R., Blassioli-Moraes, M.C., Borges, M., dados não publicados). Verificou-se que alguns parâmetros (temporais e espectrais) dos sinais vibratórios dos percevejos são mais significativos que outros, mas ainda não foram determinados quais desses parâmetros contribuem para transmitir informação entre os indivíduos (Laumann, R., Blassioli-Moraes, M.C., Borges, M., dados não publicados).

O objetivo deste capítulo foi determinar se mudanças na composição temporal do canto da fêmea que determina a formação do dueto (FS-1b) interferem no reconhecimento e resposta dos machos. Desta maneira avaliar-se-á a hipótese que: variações nos padrões temporais dos sinais vibratórios favorecem o isolamento reprodutivo entre Chinavia ubica e Chinavia impicticornis.

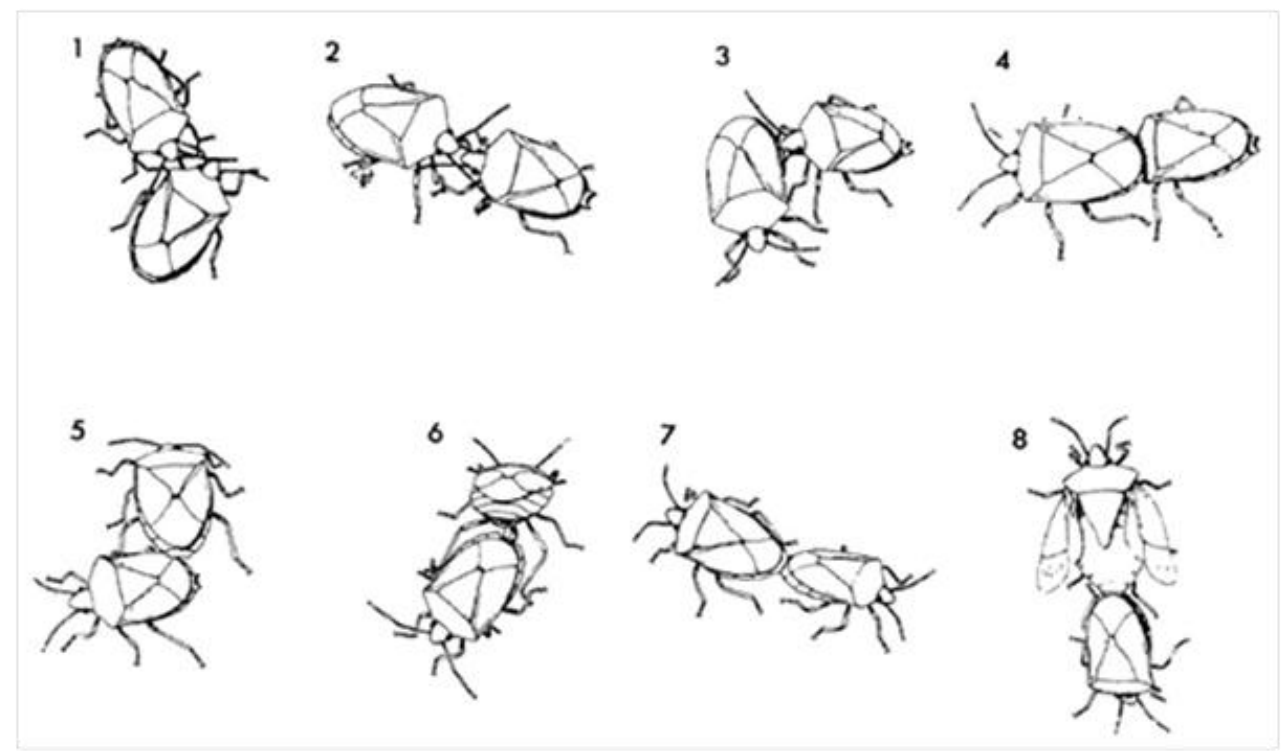

Figura 3: Comportamento de corte em Pentatomidae. Sequência de comportamento de corte de Nezara viridula. (Boges et al, 1987). 1: Aproximação do macho; 2, 3: Antenação; 4: Macho levanta o abdômen da fêmea; 5: Macho se direciona para a cópula; 6,7: Cópula; 8: Macho bate as asas. 


\section{Chinavia impicticornis}

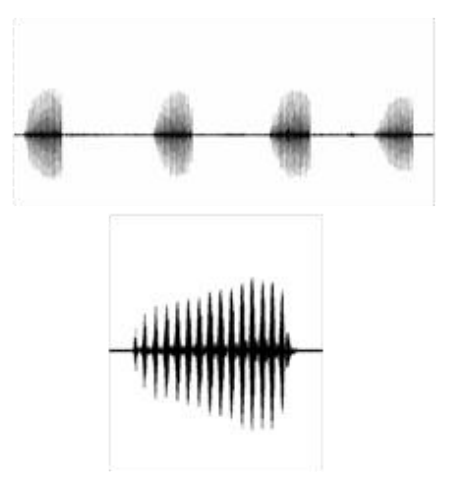

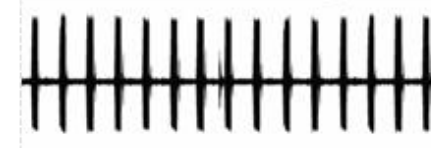
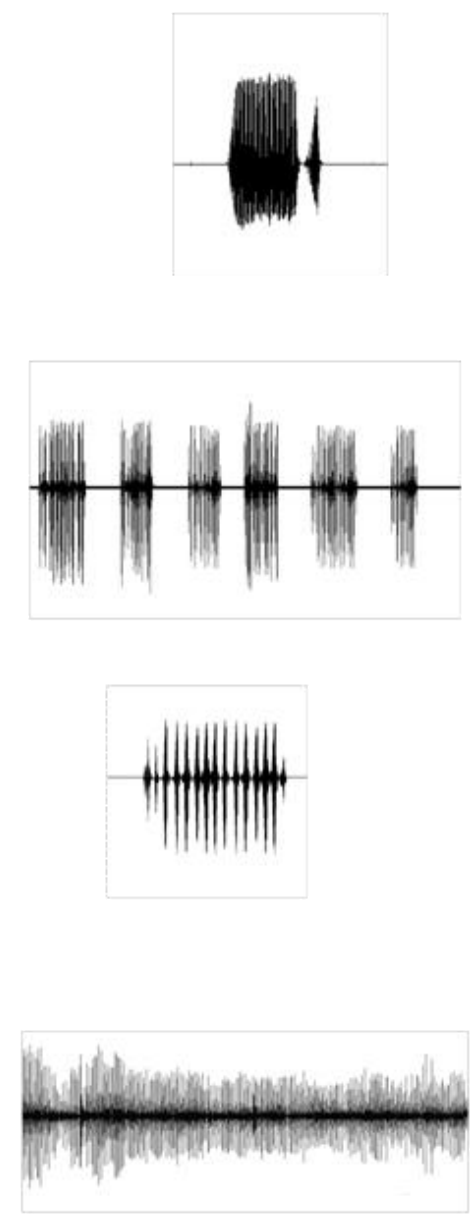

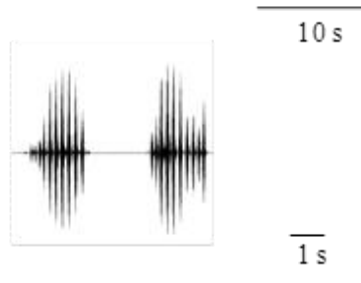

MS-2

Chinavia ubica

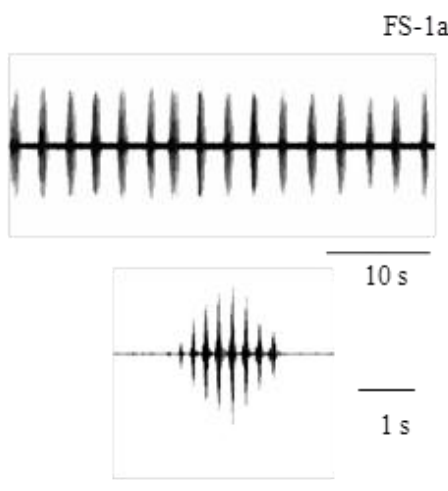

FS-1b
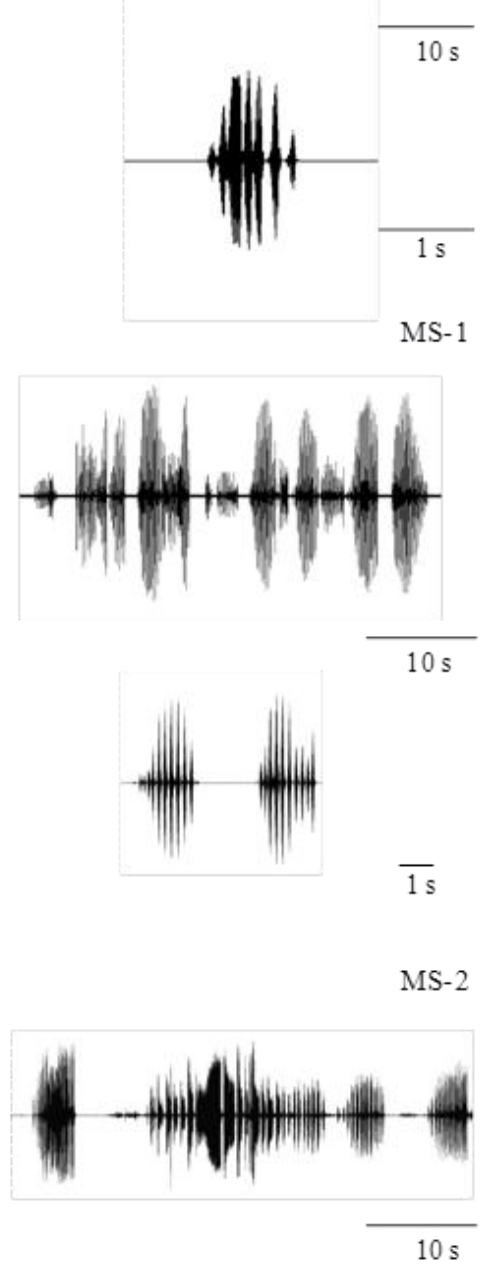

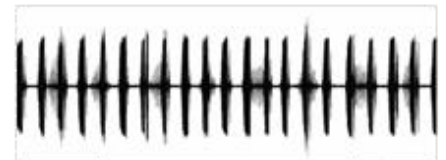

Figura 4: Repertorio de sinais de Chinavia impicticornis e Chinavia ubica identificado por Laumann, Moraes e Borges (dados não publicados). FS-1a: canto 1 da fêmea (chamamento), FS-1b: canto 2 da fêmea (chamamento/dueto), MS-1: Canto 1 do macho (dueto), MS-2: canto 2 do macho, acasalamento/corte. 


\subsection{Hipótese:}

1. Variações nos padrões temporais nos sinais vibratórios favorecem o isolamento reprodutivo entre Chinavia impicticornis e Chinavia ubica;

\subsection{Material e métodos}

\subsubsection{Plantas e insetos}

As colônias de percevejos $C$. ubica e $C$. impicticornis, estabelecidas previamente no Laboratório de Semioquímicos na Embrapa - Cenargen, foram mantidas com dieta natural a base de sementes de girassol, grãos de soja, amendoim cru e vagem, na sala de criação do laboratório. Ninfas e adultos foram mantidos em gaiolas separadas, em sala climatizada $\left(28^{\circ} \mathrm{C}\right.$ e $60 \%$ UR) com fotoperíodo de $14 \mathrm{hL}: 10 \mathrm{~h}$. Após a última muda os adultos foram separados por sexo e mantidos em gaiolas distintas em salas separadas e climatizadas. Os adultos foram utilizados nos bioensaios quando completaram 10 dias de idade adulta, quando atingem a maturidade sexual (Silva et al., 2015).

Os experimentos foram conduzidos em plantas de feijão Phaseolus vulgaris. As sementes foram plantadas em vasos de plástico de $10,5 \mathrm{~cm}$ de altura e $11 \mathrm{~cm}$ de diâmetro, preenchidos de solo estéril, enriquecido com NPK 10:10:10, e substrato para crescimento de plantas (Tropstrato HA Hortaliças) misturados em proporções iguais. Estes vasos foram mantidos em casa de vegetação para germinação e crescimento, à temperatura de $27^{\circ} \mathrm{C}$ e fotoperíodo de $14 \mathrm{~h}$ de fotofase, quando necessário completo com iluminação artificial.

Todas as plantas foram usadas em estágio vegetativo, com aproximadamente 15 dias. Neste estágio fenológico as plantas de feijão são caracterizados por duas folhas unifolioladas e dois trifólios e possuem de 15 a $20 \mathrm{~cm}$ de altura (Laumann et al., 2011).

\subsubsection{Montagem dos sons artificiais}

Os sinais vibratórios artificiais foram sintetizados utilizando a função Synthesis do programa Sound Forge 4.5 (Sonic Foundry Inc., Madison, Wisconsin, U.S.A.). Testes iniciais foram realizados com os sons artificiais baseados na canção de chamamento (FS1) de fêmeas de Chinavia ubica e Chinavia impicticornis, porém, machos de ambas as espécies não responderam aos estímulos artificiais nem a canção controle (canção original de chamamento de ambas as espécies gravadas por Laumann, R., Blassioli-Moraes, M.C., Borges, M., dados não publicados). Dessa forma, os cantos de estímulo foram montados 
considerando as canções originais de dueto (FS2) de fêmeas de Chinavia ubica e Chinavia impicticornis. Para síntese dos estímulos foram criados sinais considerando a frequência dominante do sinal de cada espécie e com as alterações das características temporais em relação às dos sinais naturalmente emitidos pelos insetos.

O trem de pulso do canto original de fêmeas dessas duas espécies é caracterizado por possuir o primeiro pulso mais longo seguido de pulsos adicionais curtos (Figura 4).

Baseado nessas características (canto Fs-1b; Figura 4) os seguintes cantos artificiais foram montados (Tabela 1; Figura 5 A e B):

Sinal artificial 1 (SA1): com o tempo de duração do canto natural sem os pulsos adicionais.

Sinal artificial 2 (SA2): com metade do tempo de duração do primeiro pulso com os pulsos adicionais possuindo tempo de duração original.

Sinal artificial 3 (SA3): com metade do tempo de duração do primeiro pulso sem os pulsos adicionais.

Sinal artificial 4 (SA4): com dobro do tempo de duração do primeiro pulso com os pulsos adicionais possuindo tempo de duração original.

Sinal artificial 5 (SA5): com o dobro do tempo de duração do primeiro pulso sem os pulsos adicionais.

Controle: canto natural de cada uma das espécies.

Tabela 1: Características temporais dos sinais montados artificialmente

\begin{tabular}{lccc}
\hline Canto & $\begin{array}{c}\text { Tempo de Duração do Tempo de Duração dos } \\
\text { Pirmeiro Pulso (ms) }\end{array}$ & $\begin{array}{c}\text { Frequência } \\
\text { Pulsos Adicionais (ms) } \\
\text { Dominante (Hz) }\end{array}$ \\
\hline SA1 C.u & 1151 & 158 & 112 \\
SA2 C.u & 575,5 & & 112 \\
SA3 C.u & 575,5 & 158 & 112 \\
SA4 C.u & 2302 & & 112 \\
SA5 C.u & 2302 & 40 & 112 \\
SA1 C.i & 1094 & & 82 \\
SA2 C.i & 547 & 40 & 82 \\
SA3 C.i & 547 & & 82 \\
SA4 C.i & 2188 & & 82 \\
SA5 C.i & 2188 & & \\
\hline
\end{tabular}




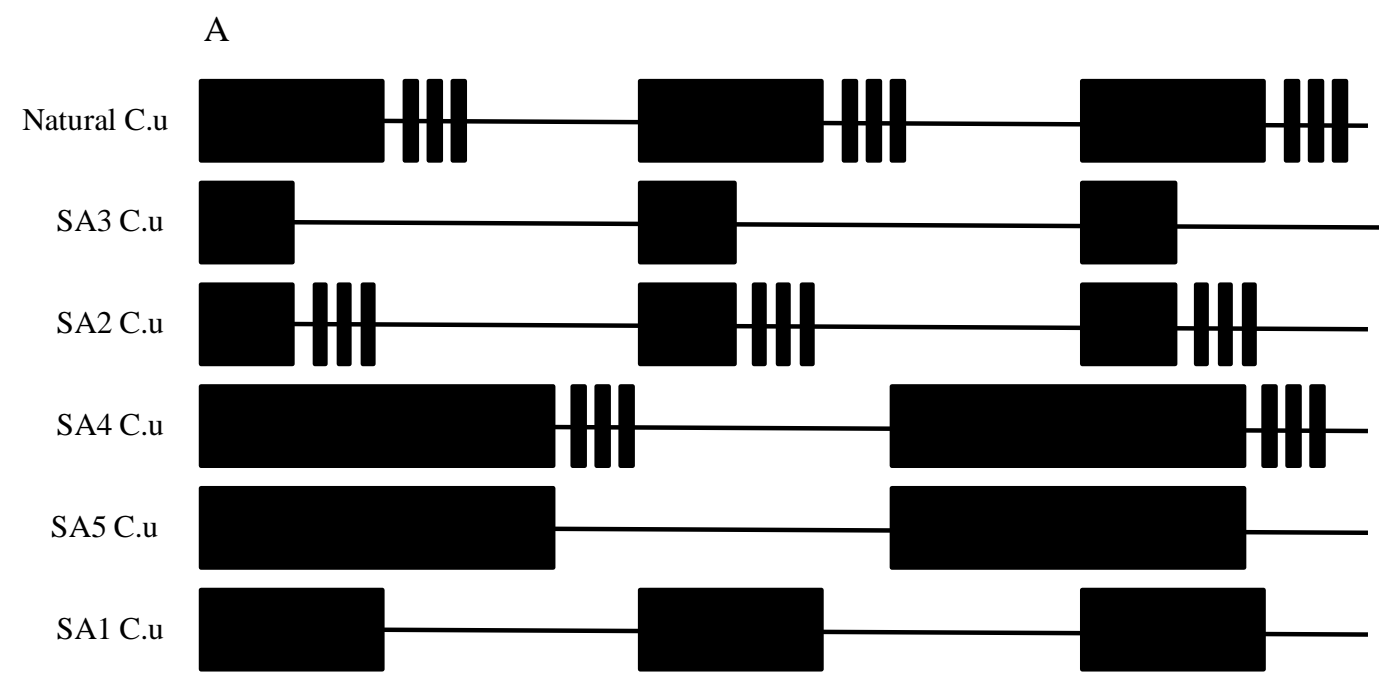

B

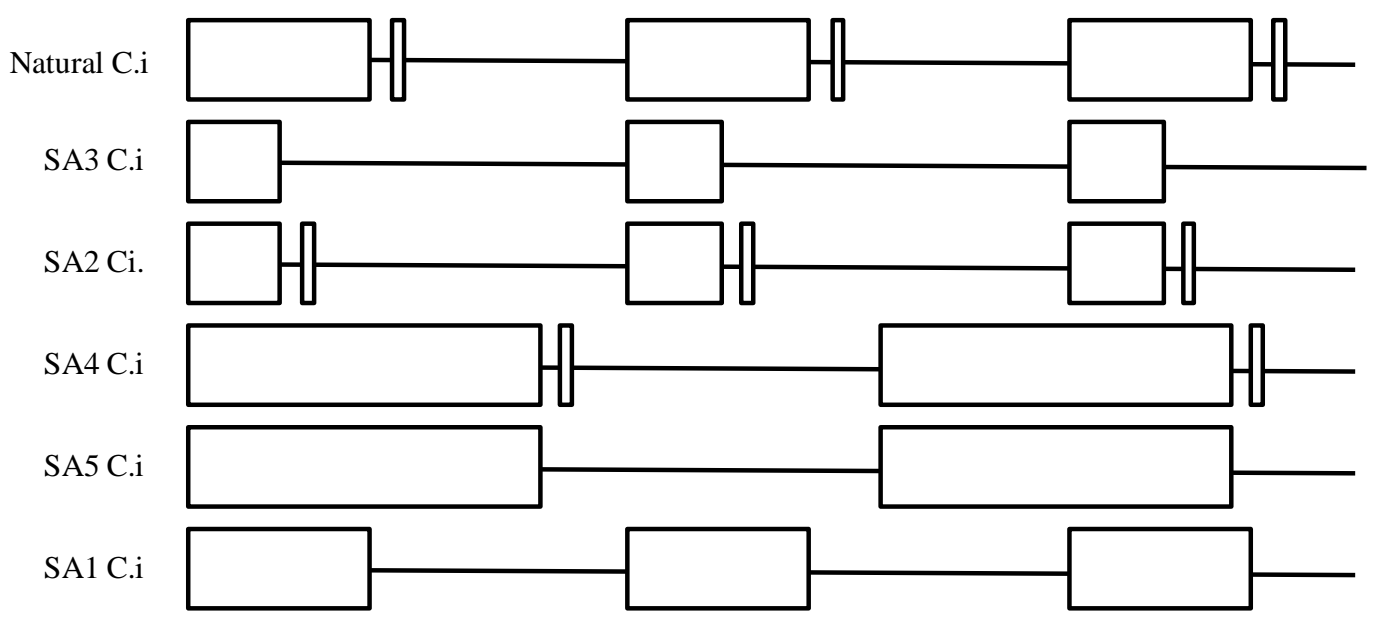

Figura 5: Esquema de oscilogramas representando os cantos montados artificialmente para Chinavia ubica (A) e Chinavia impicticornis (B). Natural (sinal emitido pelos insetos e registrado num alto falante); Sinal Artificial 1 com o mesmo tempo de duração do canto natural sem os pulsos adicionais (SA1); Sinal Artificial 2 com metade do tempo de duração do primeiro pulso com os pulsos adicionais (SA2); Sinal Artificial 3 com metade do tempo de duração do primeiro pulso sem os pulsos adicionais (SA3); Sinal Artificial 4 com dobro do tempo de duração do primeiro pulso com os pulsos adicionais (SA4); Sinal Artificial 5 com o dobro do tempo de duração do primeiro pulso sem os pulsos adicionais (SA5).

\subsubsection{Reprodução dos sinais e resposta dos machos.}

Todos os experimentos foram conduzidos na Embrapa Recursos Genéticos e Biotecnologia (Brasília, DF, Brasil) em uma sala com isolamento acústico, as plantas usadas para a transmissão dos sinais foram colocadas sobre uma mesa a prova de choque para diminuir o ruído ambiental. Observações e gravações foram conduzidas entre 10:0018:00, quando a maior parte das atividades de acasalamento foram observadas em experimentos preliminares. 
Os experimentos foram conduzidos em substratos naturais, plantas de feijão, onde machos de ambas as espécies foram colocados alternadamente e onde os sinais artificiais e naturais foram reproduzidos para estimular os insetos.

Machos de cada espécie foram colocados nas plantas numa das folhas trifoliadas e seu comportamento observado por um período de 20 minutos. Ao mesmo tempo em que os machos foram colocados nas plantas os sinais de estímulo previamente descritos foram reproduzidos em forma contínua durante todo o período experimental. O desenho experimental foi completamente aleatorizado $(n=20$ machos avaliados para cada sinal artificial e espécie) com alternância dos sinais avaliados e dos machos de cada espécie. Adicionalmente, para avaliar as condições fisiológicas em cada dia de experimentação, ou seja, se os insetos respondiam normalmente aos sinais emitidos, um grupo de 3 a 5 machos de cada espécie foi avaliado com os sinais naturais das fêmeas (sinais controle) e posteriormente uma sub-amostra de 20 machos avaliados com este sinal foi selecionada em forma aleatória para as análises estatísticas. Para retransmitir os sinais foi utilizado um computador com placa de som externa (Creative, Sound Blaster X-fi 5.1 Pro) e o software Sound Forge. A transmissão dos sinais para as plantas foi realizada utilizando um reprodutor eletromagnético de sinais vibratórios tipo "minishaker", (Bruel\&Kjaer, Naerum, Denmark, Modelo 4810), conectado à placa de som. As vibrações geradas no "minishaker" foram transmitidas às plantas acoplando um alfinete entomológico (Nro 2) na superfície vibratória do equipamento, sendo que uma das extremidades do alfinete foi introduzida no caule da planta a aproximadamente $10 \mathrm{~cm}$ desde a superfície do solo (Figuras 7).

Os sinais de resposta emitidos pelos machos foram registrados utilizando um acelerômetro piezoelétrico (1000 mV/g; Brüel \& Kjaer, type 4508), acoplado à planta na região do caule e a $5 \mathrm{~cm}$ do ponto de emissão dos sinais. Os sinais foram capturados pelo acelerômetro digitalizados por uma placa de som externa (Edirol-Roland- 24bits-96 KHZ, modelo UA-25EX) e armazenados num computador através do software Coll Edit Pro (Syntrillium Software 2001, a 24-bit, 96-kHz, 100-dB relação sinal/ruído) e analisados com o software Sound Forge 6 (Sonic Foundry Inc., Madison, WI). A gravação foi iniciada assim que o inseto foi colocado na planta para não perder o primeiro sinal de resposta. Caso o inseto não respondesse após 10 minutos de experimentação era substituído por outro e o bioensaio considerado sem resposta. A emissão dos sinais foi monitorada com fones de ouvido durante todo o período dos bioensaios.

Para as análises foram considerados proporção de machos respondendo a cada sinal reproduzido; orientação à fonte de som, considerando como resposta positiva 
quando o macho se movimenta em direção ao caule com o alfinete inserido; tempo de latência (segundos), considerando o tempo desde o inicio do experimento até a emissão do primeiro sinal pelos machos; duração do canto, tempo em segundos em que o macho mantém a emissão de sinais vibratórios; proporção de trens de pulsos de resposta em relação aos trens de pulsos de estimulo (sinais artificiais). Adicionalmente, para os tratamentos onde ao menos dois machos responderam aos sinais retransmitidos foram analisadas as características dos sinais emitidos considerando: tempo de duração do trem de pulsos (tempo em milissegundos desde o início até a finalização do trem de pulsos); tempo de repetição (intervalo em milissegundos desde início de um trem de pulsos até início do seguinte trem de pulsos); e frequência dominante (frequência com maior amplitude, em $\mathrm{Hz}$ ).

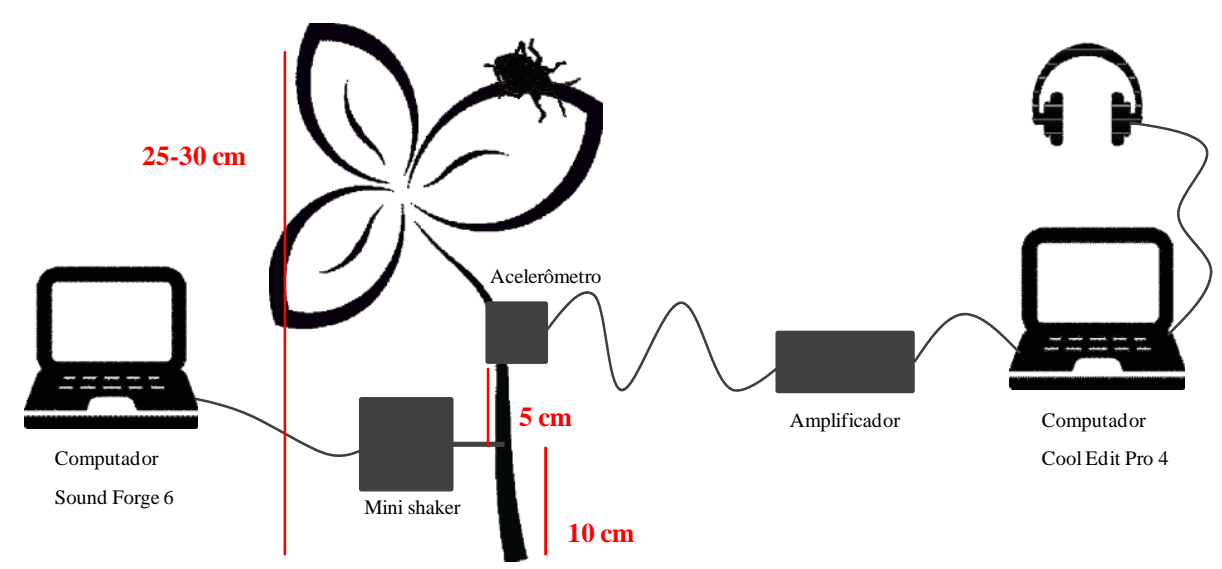

Figura 6: Representação esquemática da montagem dos experimentos com reprodução de sinais vibratórios utilizando um reprodutor eletromagnético (mini-shaker) e um acelerômetro para registro dos sinais emitidos pelos insetos avaliados.

\subsubsection{Análises Estatísticas}

A relação entre respostas e orientação a sinais artificiais em relação aos sinais naturais foi avaliada mediante o cálculo da razão de probabilidade (odd ratios) entre cada tratamento e controle (sinal natural). Utilizando a metodologia descrita em Rumel (1986) e Szumilas (2010) foram calculados as razões de probabilidade e seus respectivos intervalos de confiança (95\%). As razões de probabilidade e o IC95\% indicam a chance de resposta aos sinais artificiais em relação aos sinais naturais e, se resultam $<1$ indicam probabilidade de resposta inferior em relação aos sinais naturais, $=1$ indicam a mesma resposta em relação aos sinais naturais, e $>1$ indicam probabilidade de resposta superior em relação aos sinais naturais. 
Para avaliar o tempo de latência e duração dos cantos dos machos em relação a cada sinal artificial foram realizados análises de variância (ANOVA) e quando necessário os valores médios entre os tratamentos foram comparados utilizando teste de Tukey, previamente às análises os dados foram avaliados para comprovar a distribuição normalr . Os valores médios dos parâmetros temporais (duração do trem de pulsos e tempo de repetição do trem de pulsos) e espectrais (FD) foram comparados utilizando uma análise de modelos lineares mistos. No modelo foi incorporado o tratamento (tipo de sinal de estímulo) e um fator aleatório (indivíduo). Para conduzir as análises foi utilizado o pacote lme4 e os valore de probabilidade e intervalos de confiança foram calculados utilizando o método de Monte Carlo via cadeia de Markov com 10000 aleatorizações. A significância entre os valores dos parâmetros obtidos em cada tratamento em relação ao tratamento controle foram estabelecidos com um teste t. Para comparar a relação entre trem de pulsos emitidos pelos machos em relação ao número total de trem de pulsos de estímulo emitidos (tratamentos) foi utilizado um modelo linear generalizado com distribuição binomial de erros e tratamento (tipo de sinal de estímulo) como fator fixo. Todas as análises foram executadas utilizando a plataforma R 2.14.2 (R Development Core Team, 2012).

\subsection{Resultados}

Quando analisada a resposta de ambas as espécies a sinais naturais e artificiais foi observado que as mudanças nos padrões temporais reduzem significativamente a proporção de machos que responderam emitindo sinais vibratórios durante o período de estimulação (Figura 8A e B). Em C. ubica a razão de probabilidade da resposta a sinais artificiais em relação aos sinais naturais foram em todos os casos significativamente menores (Tabela 2), o mesmo foi observado para os machos de C. impicticornis com exceção do sinal SA5 C.i que resultou não significativamente diferente (Tabela 2). Um padrão similar de resposta foi encontrado para machos de ambas as espécies quando se considerou orientação em relação à fonte de emissão dos sinais de estímulo (Figura 8, Tabela 2). 
Tabela 2: Razão de probabilidades (Odd ratios) e IC 95\% para machos de C. ubica e C. impicticornis em resposta a sinais artificiais de fêmeas de cada espécie (FS1b) em relação aos sinais naturais.

\begin{tabular}{ccc}
\hline Tratamento & Resposta & Atração \\
\cline { 1 - 1 } C. ubica & & 0,063 \\
SA3 C.u & NA & $(0,013-0,29)$ \\
& 0,017 & 0,063 \\
SA2 C.u & $(0,002-0,17)$ & $(0,013-0,29)$ \\
& 0,017 & 0,107 \\
SA5 C.u & $(0,002-0,17)$ & $(0,025-0,46)$ \\
& NA & 0,063 \\
SA4 C.u & 0,003 & $(0,013-0,29)$ \\
& & 0,022 \\
SA1 C.u & $(0,0002-0,05)$ & $(0,0013-0,13)$ \\
\cline { 1 - 1 } C.impicticornis & 0,0132 & \\
\cline { 1 - 2 } SA3 C. $i$ & $(0,0013-0,1089)$ & NA \\
& 0,0093 & 0,0196 \\
SA2 C. $i$ & $(0,0009-0,0767)$ & $(0,003-0,219)$ \\
& $\mathbf{0 , 2 1 1}$ & 0,037 \\
SA5 C.i & $(\mathbf{0 , 0 2 1}-\mathbf{2 , 0 5 3 )}$ & $(0,0063-0,219)$ \\
SA4 C.i & 0,00929 & 0,0278 \\
& $(0,0008-0,0766)$ & $(0,0045-0,172)$ \\
SA1 C.i & 0,0059 & NA \\
\hline
\end{tabular}

Considerando o tempo de latência (tempo transcorrido desde o inicio do experimento até o momento em que o macho iniciou a resposta aos sinais de estímulo emitindo sinais vibratórios) e duração do canto (tempo em que o macho se manteve emitindo sinais vibratórios desde o momento em que emitiu o primeiro sinal) foi observado que machos de C. ubica demoraram significativamente mais tempo para responder aos sinais artificiais quando o pulso principal tinha duração dupla (SA5 C.u) em relação à duração do pulso natural (Anova, $\mathrm{F}_{2,26}=4,18 \mathrm{P}=0,03$ e teste de Tukey $\mathrm{P}<$ 0.05) (Figura 9A). Da mesma forma ao considerar a duração do canto foi observado que os sinais naturais estimulam os machos de C. ubica a manter a emissão de sinais vibratórios por um período de tempo maior (Anova $\mathrm{F}_{2,25}=48.8 \mathrm{P}<0.001$ e teste de Tukey $\mathrm{P}<0.05$ ) (Figura 9A). Já em C. impicticornis o tempo de latência não foi significativamente diferente entre os tratamentos e o controle $\left(\mathrm{F}_{5,42}=1,106 \mathrm{P}=0,372\right)$ e os sinais artificiais não estimularam os machos a emitir sinais por um período maior de tempo $\left(\mathrm{F}_{4,40}=1,617 \mathrm{P}=0,189\right)$ (Figura $\left.9 \mathrm{~B}\right)$.

Para avaliar se os cantos dos machos variam em relação aos cantos de fêmeas alterados em relação ao canto natural foram considerados diferentes parâmetros temporais 
e espectrais. Machos de C. ubica mostraram variações nos tempos de repetição e número de pulsos emitidos em relação ao número de pulsos artificiais utilizados como estímulo. No caso de tempo de repetição os machos estimulados com sinais artificiais com duração de pulso principal reduzido à metade (SA2 C.u) e com duração do pulso principal duplicado (SA5 C.u) em relação ao sinal natural mostraram tempos de repetição dos trens de pulsos maiores em relação aos emitidos em resposta aos sinais naturais (SA2 C.u $t=$ $2.75 \mathrm{P}=0.006$ e SA5 C.u t= 3.07 P = 0.002) (Figura10A). Quando considerada a relação entre número de trem de pulsos emitidos pelos machos e número de trem de pulsos artificiais utilizados para estimulá-los foi observado que os machos de C. ubica aumentaram o número de pulsos emitidos quando o sinal de estímulo foi o sinal artificial com duração de pulso principal duplicado (SA5 C.u) em relação ao sinal natural (z=3.39 $\mathrm{P}<0.001)$ e diminuíram o número de pulsos emitidos quando o sinal de estímulo foi o sinal artificial com duração de pulso reduzido à metade (SA2 C.u) em relação ao sinal natural $(\mathrm{z}=7.19 \mathrm{P}<0.001)$ (Figura 10A).

Já machos de C. impicticornis mostraram variações tanto nos parâmetros temporais quanto nos parâmetros espectrais analisados. Os machos estimulados com sinais artificiais com a duração do pulso principal reduzido a metade sem os pulsos adicionais ( $\mathrm{SA} 3 \mathrm{C} . \mathrm{i} \mathrm{t}=3,07 \mathrm{P}=0,002$ ), sinais artificiais com tempo de duração reduzido a metade com os pulsos adicionais ( $\mathrm{SA} 2 \mathrm{C} . \mathrm{i} \mathrm{t}=3,05 \mathrm{P}=0,002$ ) e com o dobro da duração do pulso principal com os pulsos adicionais (SA4 C.i t $=2,64 \mathrm{P}=0,008$ ) mostraram duração do trem de pulso menores em relação aos sinais naturais (Figura 10B). Mostraram maiores tempos de repetição ao serem estimulados com sinais artificiais com duração do pulso principal dobrada sem os pulsos adicionais (SA5 C.i t $=3,36 \mathrm{P}=0,8$ ) e sinais artificiais com mesma duração do sinal natural sem os pulsos adicionais (SA1 C.i t $=2,65 \mathrm{P}=0,008$ ) (Figura 10B). Os machos de C. impicticornis mostraram menor frequência dominante quando estimulados com sinais artificiais em que a duração do pulso principal foi reduzida a metade sem os pulsos adicionais (SA3 C.i t $=2,11 \mathrm{P}=$ 0,03), dobro da duração do pulso principal com os pulsos adicionais (SA4 C.i t $=2,97 \mathrm{P}=$ 0,03 ) e duração do pulso principal dobrada sem os pulsos adicionais (SA5 C.i t $=7,16$ $\mathrm{P}=0,000)$ em relação ao sinal natural. Além disso, quando considerada a relação entre número de trem de pulsos emitidos pelos machos e número de trem de pulsos artificiais utilizados para estimulá-los foi observado que os machos de C. impicticornis diminuíram significativamente número de pulsos emitidos quando os sinais de estímulo foram os sinais artificiais com a duração do pulso principal reduzido a metade sem os pulsos adicionais (SA3 C.i $\mathrm{t}=0,000135 \mathrm{P}<0,02$ ) e sinais artificiais com mesma duração do sinal natural sem os pulsos adicionais (SA1 C.i $\mathrm{t}=0,05 \mathrm{P}<0,01$ ) (Figura 10B). 

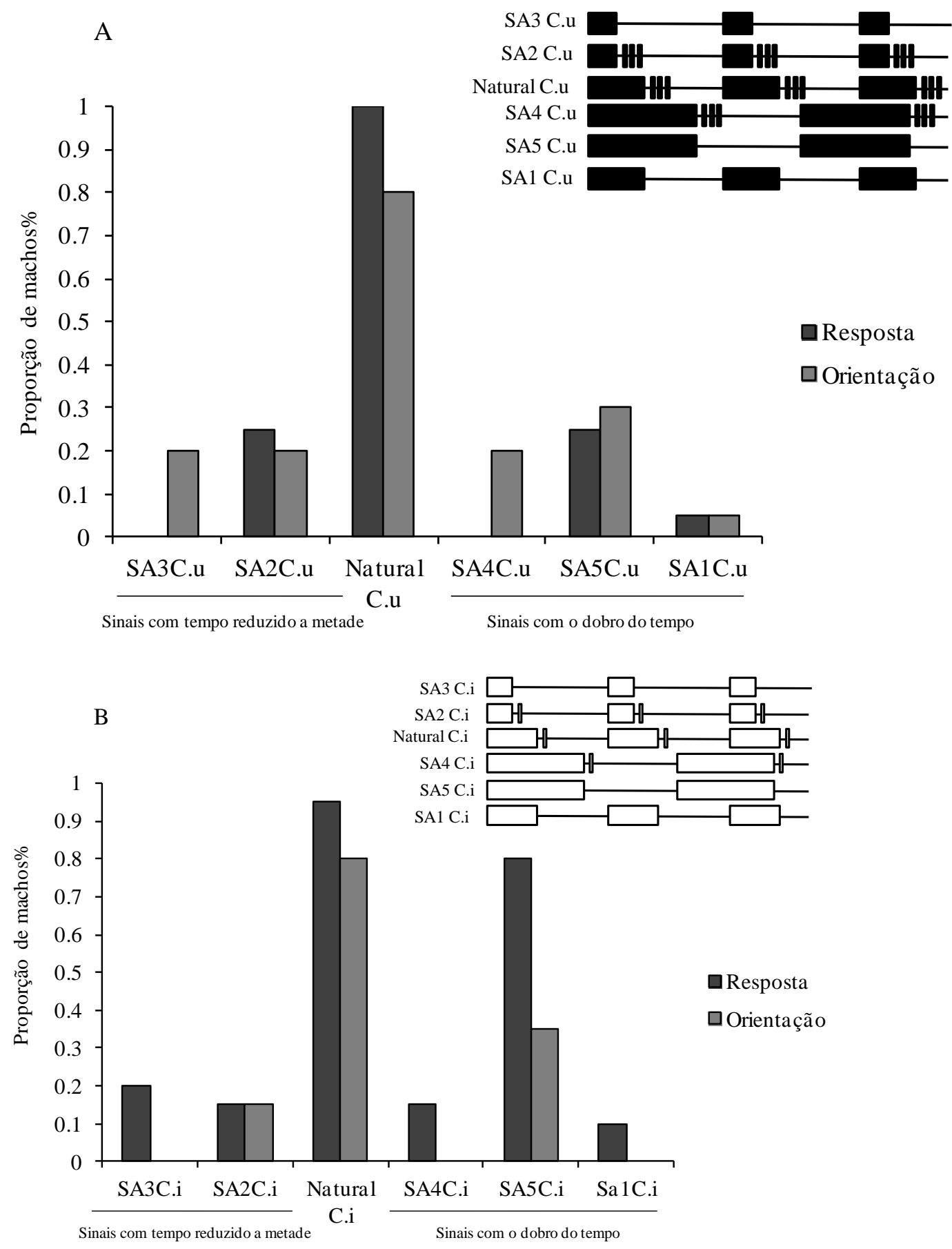

Figura 7: Proporção de machos de C. ubica (A) e de C. impicticornis (B) que responderam aos sinais artificiais e que se orientaram em direção à fonte de emissão do sinal. 


\section{A}

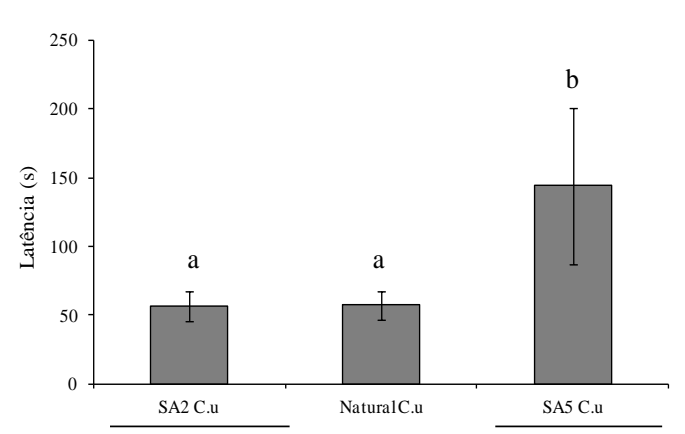

Sinal com tempo reduzido a metade Sinal com o dobro do tempo

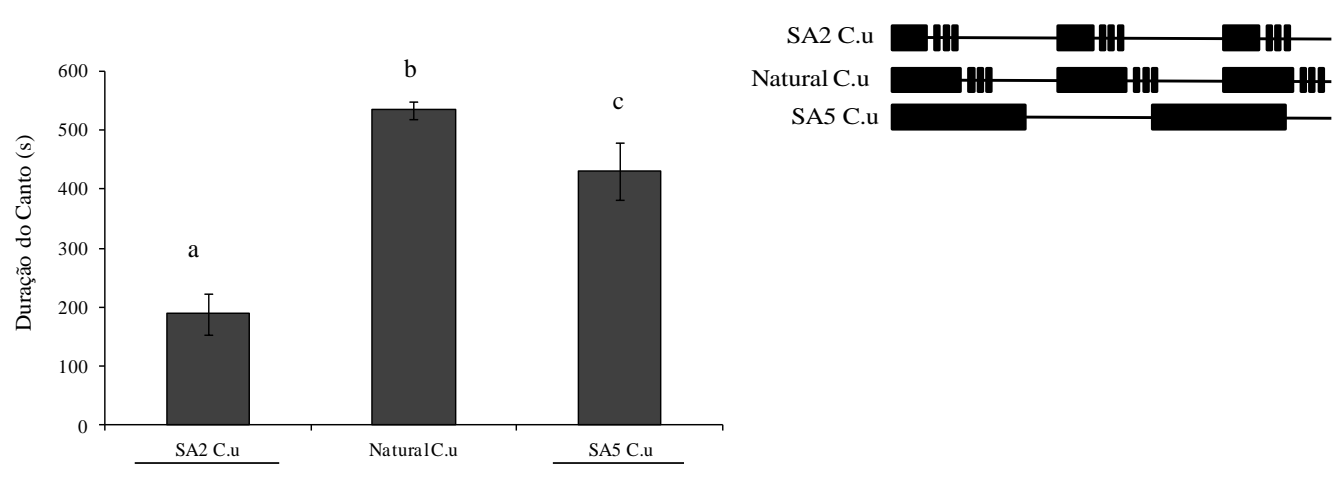

Sinal com tempo reduzido a metade Sinal com o dobro do tempo
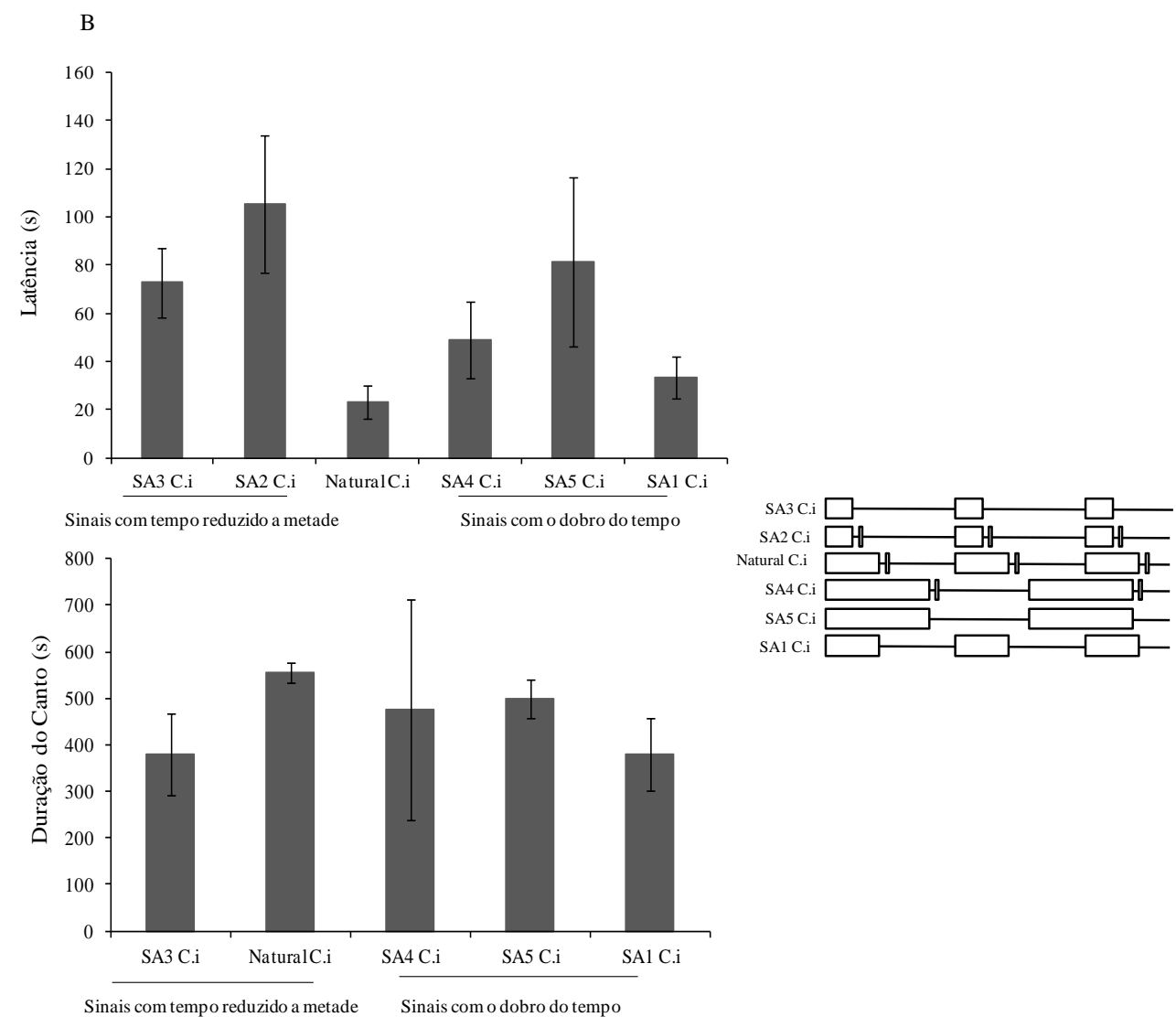

Figura 8: Tempo de latência e duração do canto de C. ubica (A) e C. impicticornis (B) em respostas aos sinais estímulo.Letras diferentes indicam respostas significativamente diferentes e as barras indicam o erro padrão. 

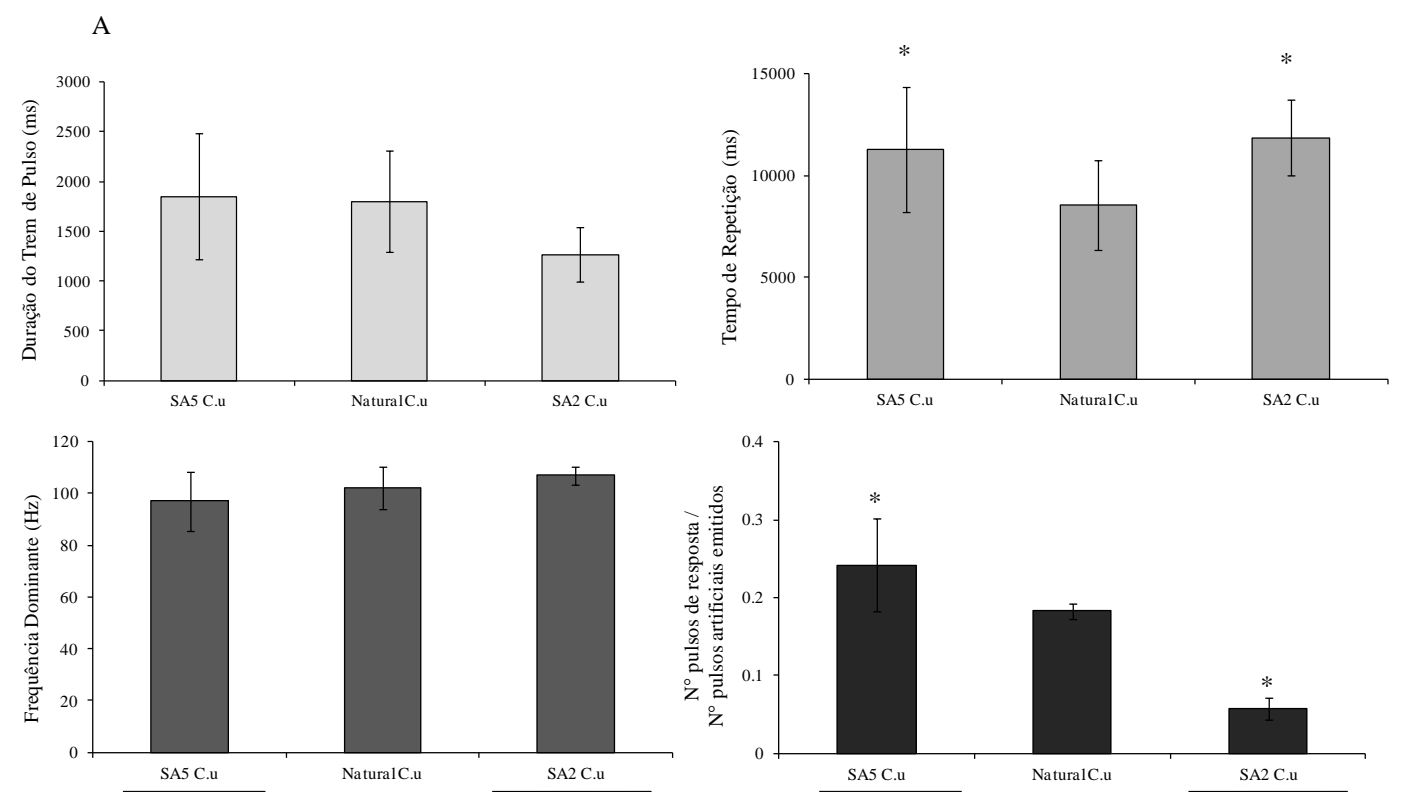

Sinais com tempo reduzido a metade Sinais com o dobro do tempo

Sinais com tempo reduzido a metade

Sinais com o dobro do tempo

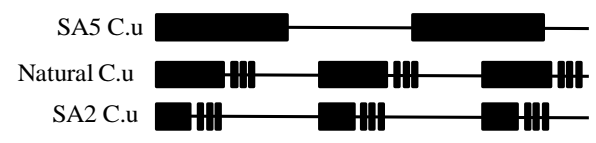

B
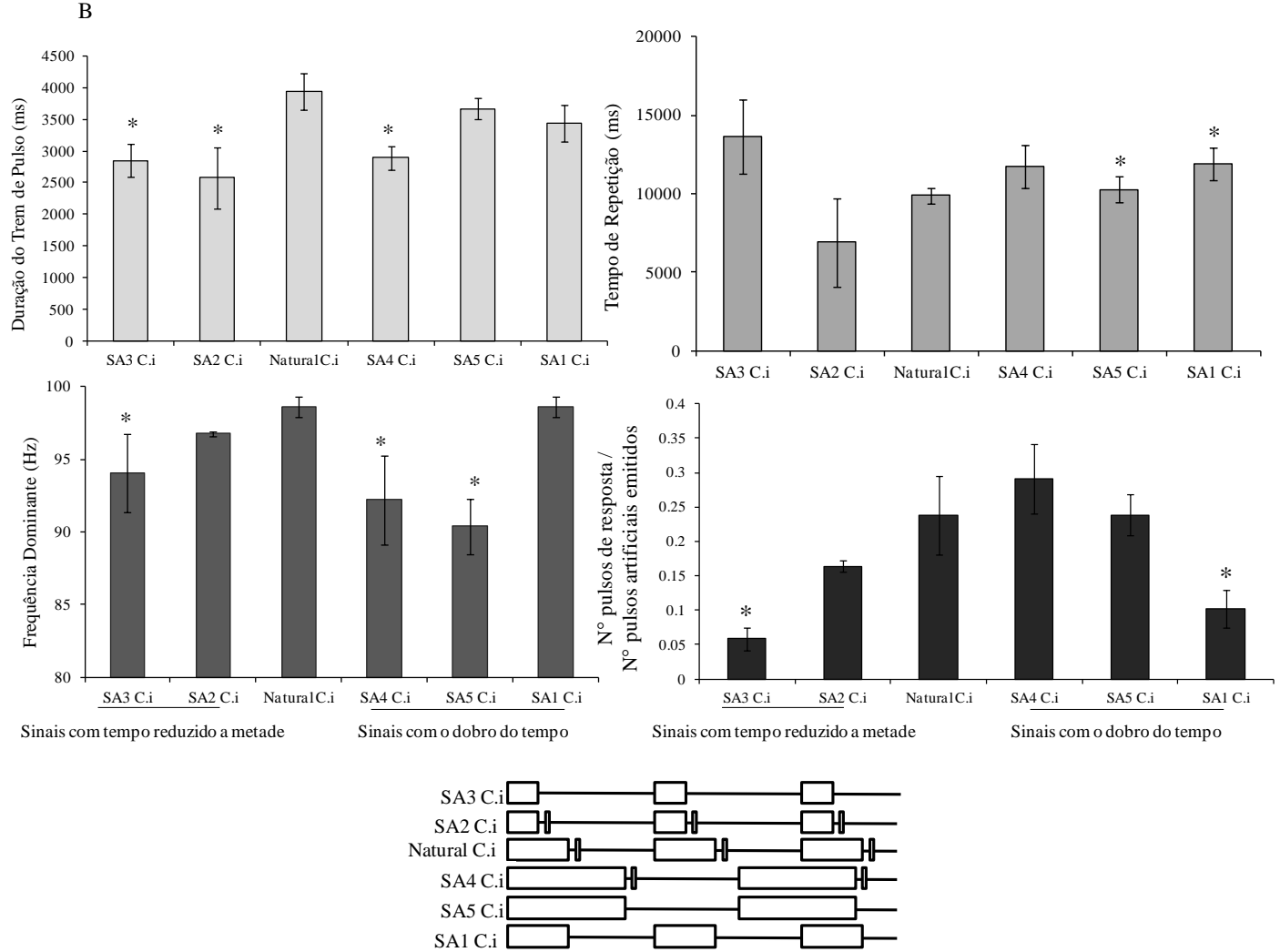

Figura 9: Duração dos trens de pulsos de resposta, tempo de repetição, frequência dominante e proporção dos números de reposta em relação ao número de pulsos emitidos de $C$. ubica (A) e C. impicticornis (B) aos sinais artificiais. Os asteriscos indicam diferencias significativas nos valores dos parâmetros em relação ao sinal natural. 


\subsection{Discussão}

Os resultados indicam que alterações temporais nos cantos das fêmeas diminuem a capacidade de reconhecimento e de emissão de sinais de resposta pelo macho coespecífico. Quando os machos de ambas as espécies foram estimulados com sinais naturais característicos das fêmeas de cada espécie, mostraram respostas estereotipadas com emissão do sinal de chamamento (MS-1), caracterizado por um trem de pulsos com padrões temporais e espectrais característicos e bem conservados. Desta maneira os resultados obtidos sugerem que os parâmetros temporais dos sinais vibratórios de ambas as espécies são determinantes para estabelecer e manter a comunicação intraespecífica e contribuem decisivamente para o sucesso reprodutivo dos indivíduos.

Os parâmetros temporais dos sinais vibratórios são específicos tanto para espécie e sexo em diferentes espécies de percevejos (Čok1 \& Virant-Doberlet, 2003, Moraes et al., 2005, Čokl, 2008), inclusive nas espécies de Chinavia estudadas (Laumann, R.A., Blassioli-Moraes, M.C., e Borges, M., dados não publicados). É possível inferir que os pulsos adicionais não estimulam machos de C. ubica, uma vez que os dois estímulos para os quais os machos emitiram sinais vibracionais (SA2 C.u e SA5 C.u) possuem aproximadamente o mesmo tempo total de duração do trem de pulso entre si e, consequentemente, tempo de repetição. Dessa forma, os machos desta espécie mostraram responder melhor para sinais artificiais com duração do trem de pulso mais longa. Este resultado coincide com o observado para machos do percevejo verde, Nezara viridula, que também apresentam resposta reduzida quando estimulados por sinais artificiais com características espectrais alteradas (Žunik et al., 2011). Neste caso específico foi demonstrado que a diminuição da duração dos parâmetros temporais tem efeitos inibitórios maiores que o aumento na duração dos mesmos e em ambos os casos a resposta dos machos desta espécie é reduzida em relação aos sinais naturais (Žunik et al., 2011; Groot et al., 2011). Isso está de acordo com Čokl et al. (1978), que sugerem que a redução da resposta aos sinais de curta duração pode ser explicado pela semelhança com a canção de chamamento do macho coespecífico.

Os machos de C. ubica também mostraram maiores tempos de repetição dos trens de pulsos quando estimulados com esses mesmos tratamentos e também aumentaram o número de pulsos emitidos quando o sinal de estímulo foi SA5 C.u e diminuíram o número de pulsos emitidos quando o sinal de estímulo foi SA2C.u. Isso sugere que os machos de C. ubica podem adaptar, dentro de certos limites, a emissão de sinais vibratórios em relação às características temporais dos cantos das fêmeas. Observações anteriores em Nezara viridula também têm indicado que os machos são capazes de 
distinguir entre canções de chamamento de coespecífico e heteroespecífico que diferem nos parâmetros temporais (duração e tempo de repetição) (Čokl et al., 1978; Miklas et al., 2001, 2003a; Hrabar et al., 2004).

Sinais de chamamento de machos de C.ubica e C.impicticornis possuem duração do trem de pulso menor que das fêmeas coespecíficas (Laumann et al., dados não publicados) o que também é característico para outras espécies de percevejos estudadas como Palomena prassina (Linnaeus, 1761), P. viridissima (Poda 1761), Acrosternum hilare, Nezara antennata, (Scott, 1974) (Čokl et al., 1978, 2001; Kon et al., 1988), Tyantha pallidovirens, (Stål, 1862), T. custator Accera (McAtee, 1919) (Hrabar et al., 2004), Chlorochroa uhleri (Stål, 1872) (Bagwell et al., 2008), C. impicticornis, Euschistus heros, Piezodorus guildinii e Thyanta perditor (Moraes et al., 2005).

Os sinais artificiais com trem de pulsos menores, avaliados neste trabalho, podem ser identificados pelos machos como sinais de machos competidores e isto pode explicar a resposta reduzida a estes sinais. Por outro lado, a maior tolerância a sinais com tempos de duração maior, segundo Žunik et al., (2011), pode estar relacionada às propriedades resonantes das plantas que originam ecos durante a transmissão dos sinais que geralmente tem como consequência a extensão da duração dos sinais (Michelsen et al., 1982; Miklas et al., 2001).

Machos de C. impicticonis não mostraram diferença nos tempos de latência e duração do canto em relação ao sinal natural, sugerindo que não percebem as diferenças nos sinais assim que começa a emissão. A baixa preferencia para o canto de dueto pode ser explicada pelas características temporais (Cokl et al., 2000; Žunik et al., 2011). Em contrapartida, após começarem a responder passaram a reconhecer os sinais, uma vez que mostraram diferenças nos parâmetros temporais em resposta a alguns sinais artificiais, apresentando duração de trens de pulso menores quando estimulados com SA3 C.i (metade da duração do pulso sem os pulsos adicionais), SA2 C.i (metade da duração do pulso com os pulsos adicionais) e SA4 C.i (dobro da duração do pulso com os pulsos adicionais), em relação ao sinal natural, mostrando não discriminar entre os estímulos de encurtamento e prolongamento dos sinais. Dessa forma, os machos de C. impicticornis parecem ser altamente seletivos em relação aos parâmetros temporais dos sinais vibratórios de fêmeas da própria espécie, enquanto que os machos de C.ubica mostraram respostas específicas conforme o tempo de duração dos sinais.

Os machos de C. impicticornis mostraram tempos de repetição maiores quando estimulados SA1 C.i (mesma duração do pulso natural sem os pulsos adicionais) e SA5 
C.i (dobro da duração do pulso sem os pulsos adicionais), além de terem diminuído significativamente o número de pulsos emitidos em relação aos pulsos artificiais quando os sinais de estímulo foram SA3 C.i e SA1 C.i. Mostrando, assim como em C. ubica, que o padrão de resposta pode adaptar-se às características temporais dos sinais de estímulo (Čokl et al., 1978; Miklas et al., 2001, 2003a; Hrabar et al., 2004).

Também foram encontradas diferenças no tempo de latência entre as canções de machos e fêmeas de Homalodisca liturata (Ball, 1901) e Graphocephala atropunctata (Signoret, 1854) (Percy et al., 2008). Diferenças na estrutura das canções de corte de machos de espécies do gênero Tibicina spp. (Homoptera: Cicadidae) agem como um sistema de reconhecimento durante o comportamento de acasalamento (Sueur \& Aubin, 2004). Segundo Rodríguez-Loeches et al. (2009) machos e fêmeas de Phoenicoprocta capistrata (Fabricius 1775) (Lepidoptera: Arctiidae) apresentam diferenças nos tempos de trens de pulsos, sendo os machos que possuem trens de pulsos mais longos. Sueur \& Aubin (2006) mostraram que baratas da espécie Elliptorhina chopardi (Lefeuvre, 1966) apresentam um sistema complexo de comunicação através do substrato e também do ar, com os machos produzindo três tipos diferentes de sinais com parâmetros temporais e de frequência distintos. Os cantos de machos e fêmeas de Karoophasma biedouwensis (Klass, 2003) foram caracterizados por Eberhard \& Picker (2008) e mostraram que as diferenças entre as canções de machos e fêmeas estão nas características temporais, as fêmeas apresentam pulsos individuais repetidos, em quanto os machos apresentam canções mais complexas com trens de pulsos que se repetem.

Assim como mostrado previamente para o percevejo verde $N$. viridula, os resultados deste trabalho indicam que machos de $C$. ubica e $C$. impicticornis são capazes de distinguir e responder seletivamente aos sinais das fêmeas coespecíficas. Esta resposta seletiva assegura o isolamento reprodutivo entre as espécies e é complementar à seletividade observada para fêmeas de ambas as espécies na resposta aos feromônios sexuais (Blassioli-Moraes et al., 2013). Desta maneira a preferência na resposta tanto a sinais vibratórios quanto a sinais químicos suporta a hipótese que a especificidade destas respostas é um fator condicionante da evolução dos sinais em percevejos (Žunik, et al., 2011).

Trabalhos futuros devem ser orientados a estabelecer a especificidade das respostas das fêmeas aos sinais dos machos e a função biológica específica de cada tipo de sinal. 


\section{Capítulo 2}

\section{Identificação e comparação de hidrocarbonetos cuticulares presentes em Chinavia ubica e Chinavia impicticornis (Hemiptera: Pentatomidae).}

\subsection{Introdução}

Os hidrocarbonetos cuticulares são compostos comuns encontrados na cutícula dos insetos e seu papel principal é a proteção contra dissecação (Blomquist \& Bagnères, 2010). Entretanto, nas últimas décadas, estudos vêm demonstrando que, devido a sua complexidade estrutural e diversidade, sua função é estendida a comunicação química, servindo como feromônio sexual, cairomônios, mimetismo químico, reconhecimento de membros de um ninho, e pista de reconhecimento de espécies, gênero e fertilidade (Blomquist \& Bagnères, 2010).

Os hidrocarbonetos cuticulares dos insetos são compostos apolares que apresentam carbono e hidrogênio em sua estrutura e podem ocorrer como uma mistura complexa de hidrocarbonetos saturados ( $n$-alcanos), hidrocarbonetos insaturados (olefinas) e hidrocarbonetos ramificados (metil-alcanos) (Lockey, 1988, Blomquist \& Bagnères, 2010). Vários estudos com ampla diversidade de espécies de insetos têm estabelecido que o principal local de biossíntese de hidrocarbonetos são as células dos corpos gordurosos, os enócitos (Lockey, 1988; Blomquist \& Bagnères, 2010). A localização anatômica dessas células varia entre as espécies de insetos e os estágios de desenvolvimento (Blomquist \& Bagnères, 2010).

O perfil de hidrocarbonetos tende a ser espécie específico (Howard, 1993 in Howard \& Blomquist, 2005), até mesmo entre espécies de um mesmo grupo, como em Drosophila (Jallon \& David, 1987) e espécies de Sarcophagidae (Braga et al., 2013), e também desempenham papel importante oferecendo informações sobre sexo, como demonstrado para moscas tsé-tsé e besouros cerambicídeos (Nelson, et al., 1986; Jallon \& David, 1987; Ginzel et al., 2003), podendo também estimular o comportamento copulatório em machos da mosca Phormia regina (Stoffolano et al., 1997).

O mimetismo químico é demonstrado por Bagnères et al. (1996) em seu trabalho com vespas parasitas. Uma rainha fecundada do parasita Polistes atrimandibularis (Zimmermann, 1930) após invadir um ninho passa a produzir o perfil de hidrocarbonetos 
do hospedeiro, Polistes biglumis bimaculatus (Christ, 1791). Após a eclosão dos soldados, hospedeiros e parasita possuem o mesmo perfil químico cuticular e a prole do invasor eclode com um perfil químico intermediário entre progenitora e membros da colônia invadida.

Em insetos sociais a composição química da cutícula é importante no reconhecimento de espécie, sexo e membros da mesma colônia (Howard et al., 1982; Peeters et al, 1999; Dietemann et al., 2003; Lucas et al., 2004; Wilgenburg et al., 2013). Além disso, o perfil de hidrocarbonetos cuticulares pode ser usado para identificar espécies crípticas, como demonstrado em Macrolophus pygmaeus (Rambur, 1939) e Macrolophus melanotoma (Costa, 1853) (Gemeno et al., 2012). E também podem desempenhar papel importante na entomologia forense, mostrando ser uma ferramenta taxonômica eficiente, especialmente quando só algumas partes dos espécimes estão disponíveis (Braga et al., 2013). Em muitos himenópteros sociais indivíduos receptivos para reprodução diferem em seu perfil químico cuticular dos indivíduos não ativos reprodutivamente (Blomquist \& Bagnères, 2010).

Além das funções anteriormente citadas tem sido demonstrado que o feromônio de algumas famílias de lepidópteros, como no caso das famílias Geometridae, Noctuidae, Arctiidae, e Lymantriidae, é derivado de hidrocarbonetos insaturados de cadeia longa presente na hemolinfa, (Jurenka \& Subchev, 2000; Bergmann et al., 2009).

No caso de percevejos (Pentatomidae) existe ainda pouca informação em relação aos hidrocarbonetos cuticulares e sua função tanto na proteção dos indivíduos quanto na comunicação. O perfil químico da cutícula dos percevejos pode apresentar diferenças tanto entre espécies quanto entre machos e fêmeas e até mesmo nos diferentes estágios de desenvolvimento (de Pasquale et al., 2007; Jackson, 1983). As diferenças entre gênero e espécie podem ainda ser utilizadas por parasitoides de ovos de percevejo verde, Nezara viridula, como pista de localização do hospedeiro (Colazza et al., 2007).

Não há nenhum estudo sobre a composição química da cutícula em Chinavia ubica e Chinavia impicticornis. Laumann et al. (dados não publicados) observaram que a etapa de antenação (Borges et al,. 1987) do comportamento de corte desses insetos pode ser importante para o reconhecimento entre indivíduos. Este comportamento pode estar relacionado a hidrocarbonetos cuticulares já que durante a antenação os receptores químicos das antenas destes insetos estão em contato direto com a cutícula.

Com isso, o objetivo deste capítulo foi comparar o perfil de hidrocarbonetos cuticulares de Chinavia ubica e Chinavia impicticornis. Desta maneira avaliar-se-á a 
hipótese que: há diferença na composição química da cutícula (hidrocarbonetos) entre as espécies Chinavia impicticornis e Chinavia ubica e entre sexo dos indivíduos. Assim este trabalho visa iniciar a compreensão da possível função de hidrocarbonetos cuticulares no comportamento reprodutivo de percevejos já que diferenças na composição dos hidrocarbonetos cuticulares podem atuar como sinais para reconhecimento específico e de sexo entre as espécies.

\subsection{Hipótese:}

Há diferença na composição química da cutícula (hidrocarbonetos) entre as espécies Chinavia impicticornis e Chinavia ubica.

\subsection{Material e Métodos}

\subsubsection{Insetos}

Os insetos utilizados foram criados na Embrapa Cenargen conforme descrito no Capítulo 1 desta dissertação. Para a extração dos hidrocarbonetos foram utilizados machos e fêmeas de Chinavia ubica e Chinavia impicticornis com 10 dias de idade adulta. Os insetos foram mantidos separados em grupos por sexo em gaiolas plásticas que eram limpas três vezes por semana, para evitar acúmulo de sujeira e contaminação.

\subsubsection{Extração de Hidrocarbonetos Cuticulares}

Várias metodologias foram testadas antes que uma fosse estabelecida.

Metodologia 1: Um a um os machos e fêmeas de C.ubica e C.impicticornis foram colocados em freezer a $-20^{\circ} \mathrm{C}$ por 10 minutos a fim de serem adormecidos. Logo após foram mergulhados individualmente por inteiro em um vial com capacidade de $5 \mathrm{~mL}$ contendo $2 \mathrm{~mL}$ de hexano bidestilado por 5 minutos. Cada amostra continha apenas 1 inseto. Foram feitas 10 repetições de cada amostra: machos de C.ubica, fêmeas de C.ubica, machos de C.impicticornis e fêmeas de C.impicticornis.

Metodologia 2: Machos e fêmeas de C.ubica e C.impicticornis foram adormecidos em fluxo de $\mathrm{CO}_{2}$ e posteriormente colocados em freezer $-20^{\circ} \mathrm{C}$ por cerca de 1 hora. Com auxílio de lupa binocular, cada inseto foi dissecado, tendo o pronoto extraído. Cada pronoto teve a parte interna levemente raspada com pinça e lavada com água destilada a fim de extrair restos de tecido (adaptado de Colazza et al., 2007). Um total de 20 pronotos de cada espécie e sexo foi inserido em um vial de capacidade de 5 $\mathrm{mL}$ contendo $2 \mathrm{~mL}$ de hexano bidestilado, ficando mergulhados por 5 minutos (adaptado 
de Colazza et al., 2007). Foram feitas 5 repetições de cada amostra: machos de C.ubica, fêmeas de C.ubica, machos de C.impicticornis e fêmeas de C.impicticornis.

Metodologia 3: O mesmo método anterior de extração foi praticado, porém os pronotos permaneceram mergulhados em hexano por 2 horas em banho Maria a $30^{\circ} \mathrm{C}$ (Colazza et al., 2007).

Os extratos obtidos com estas 3 metodologias foram pré-concentradas a $100 \mu \mathrm{L}$ em fluxo de $\mathrm{N}_{2}$. Um $\mu \mathrm{L}$ de cada amostra foi injetado em cromatógrafo gasoso (CG) (Agilent 7890, coluna apolar DB-5). Os cromatogramas obtidos das amostras extraídas pelos métodos acima descritos mostraram contaminação com aldeídos, alcanos e outros componentes das glândulas metatoráxicas, assim com lipídeos. Além disto, as análises cromatográficas mostraram baixa eficiência para extração dos hidrocarbonetos e grande variabilidade entre as amostras.

Levando em consideração estes resultados, uma nova metodologia foi desenvolvida com modificação a partir das descritas anteriormente.

Metodologia 4: Os insetos foram adormecidos em fluxo de $\mathrm{CO}_{2}$ e congelados, em frascos de vidro, em freezer a $-20^{\circ} \mathrm{C}$, dessa maneira evitou-se que os percevejos liberassem feromônio de alarme durante o manuseio, contaminando a amostra. Os insetos foram manuseados com uma pinça entomológica, lavada com álcool $70 \%$ e mantida em estufa a $60^{\circ} \mathrm{C}$. Um a um o pronoto e escutelo de cada inseto foi levemente esfregado com um cotonete hospitalar esterilizado (Absorve - Swab para coleta de amostras estéril $\mathrm{N}^{\circ}$ 23007) o qual era mergulhado previamente em n-hexano bidestilado. Após esfregar cada inseto o cotonete foi mergulhado num vial de $5 \mathrm{~mL}$ contendo $2 \mathrm{~mL}$ de $\mathrm{n}$-hexano bidestilado, foi utilizados um cotonete a cada 5 insetos. Para evitar contaminação das amostras somente a cápsula de algodão do cotonete foi mergulhada no solvente. Foram utilizados 20 insetos para cada amostra, totalizando 5 repetições de cada amostra: Machos de C. ubica, Fêmeas de C. ubica, Machos de C. impicticornis, Fêmeas de $C$. impicticornis.

As amostras foram purificadas em colunas de sílica gel. As colunas foram montadas em pipeta Pasteur de vidro, com lã de vidro em um das extremidades e preenchida com $500 \mathrm{mg}$ de sílica gel (Sigma Aldrich -230 mesh). A coluna de sílica foi condicionada com três lavagens em sequência de $3 \mathrm{~mL}$ de hexano, seguido de três lavagens com éter etílico e mais $5 \mathrm{~mL}$ de hexano. O extrato contendo os hidrocarbonetos cuticulares foi colocado na sílica gel cuidadosamente e foi eluído da coluna com $3 \mathrm{~mL}$ de $n$-hexano biestilado. Foi feita uma coluna para cada amostra. Os hidrocarbonetos eluídos 
da coluna de sílica gel foram pré-concentrados sob nitrogênio para um volume final de $100 \mu \mathrm{L}$. Para quantificação dos compostos as amostras foram pré-concentradas em fluxo de $\mathrm{N}_{2}$ a $50 \mu \mathrm{L}$ e $2 \mu \mathrm{L}$ de uma solução de etil esterato $(0,0305 \mathrm{mg} / \mathrm{mL})$ foram adicionados às amostras como padrão interno (PI). Posteriormente o volume foi corrigido novamente para $50 \mu \mathrm{L}$. Para a quantificação a área do PI, com valor de massa do composto injetado no cromatógrafo conhecido $(1,22 \mathrm{ng})$, foi comparada às áreas de cada composto mediante cálculo de regra de três simples. Os valores calculados para cada composto em cada amostra foram expressos como ng/inseto. As amostras foram analisadas em cromatógrafo gasoso (CG) (Agilent 7890, coluna apolar DB-5, 0,32 mm de diâmeto x $60 \mathrm{~m}$ de comprimento, filme 1,0 $\mu \mathrm{m}$, Supelco, Bellefonte, PA, EUA), com detector de ionização por chama (DIC) a $300^{\circ} \mathrm{C}$ e um programa na temperatura $50^{\circ} \mathrm{C} / 2 \mathrm{~min}, 5^{\circ} \mathrm{C} / \mathrm{min}$ até $200^{\circ} \mathrm{C} / 32$, mantendo a temperatura por $1 \mathrm{~min}$ e $10^{\circ} \mathrm{C} / \mathrm{min}$ até $280^{\circ} \mathrm{C} /$ mantendo a temperatura por 30min . Um microlitro de cada amostra foi injetado com Nitrogênio utilizado como gás de arraste. Para quantificação a área de cada composto foi comparada com a área do PI, para a qual o valor de massa injetado no equipamento foi conhecido $(1,22 \mathrm{ng})$, considerando fator de resposta $=1$ em relação ao PI para todos os compostos.

A identificação dos compostos foi obtida por análise em cromatógrafo gasoso (CG) acoplado a um espectrômetro de massas (CG Agilent GC7890A acoplado a um espectrômetro de massas Agilent 5975 MSD com analizador quadrupolar, coluna DB-5 $(30 \mathrm{~m} \times 0.25 \mathrm{~mm}$ ID, $0.25 \mu \mathrm{m}, \mathrm{J} \& \mathrm{~W}$ Scientific, Folsom, CA, USA, ionização por impacto de elétrons, 70-eV,). Os dados foram coletado e analisados utilizando o software MSD ChemSation Software (Agilent, USA). O padrão de fragmentação dos compostos foi comparado com os de dados catalogados em bibliotecas espectrais (NIST), e comparado com o padrão de fragmentação e do cálculo do índice de retenção (IR) com os de padrões autênticos. Para isto uma mistura de padrões de Alcanos (C9-C40, Supelco - USA) foi injetada, nas mesmas condições descritas anteriormente.

\subsubsection{Análises estatísticas}

Para avaliar se a quantidade total de hidrocarbonetos varia entre espécie e sexo foi realizado uma análise de variância (ANOVA) onde foram considerados os valores totais de hidrocarbonetos de acordo com espécie e sexo. Para verificar se existe relação entre os compostos identificados e as espécies de estudo foi realizada uma análise multivariada incorporando cada composto como uma variável e espécie e sexo como fator, a significância foi avaliada com um teste F (teste Pillai). Posteriormente foi realizada uma análise de variáveis canônicas (CVA) para determinar que compostos contribuem em maior medida para a separação dos tratamentos. Esta análise considera 
uma combinação linear das variáveis para $\mathrm{n}$ dimensões ( $\mathrm{n}=$ número de variáveis), que para simplificar normalmente se apresentam em gráficos das dimensões que carregam a maior parte da variabilidade observada (normalmente duas ou três dimensões). Os coeficientes estimados para cada variável são apresentados como vetores num gráfico de duas dimensões e aqueles com maiores valores revelam as variáveis com maior relevância para separar os diferentes níveis do fator, neste caso espécie-sexo. No gráfico também está representado a posição de cada indivíduo considerado na análise em relação às variáveis calculadas. Para conduzir as análises multivariadas os dados (quantidade de cada composto) foram transformados como $\log \mathrm{x}$.

\subsection{Resultados}

Foram identificados 14 compostos nos extratos de machos e fêmeas de ambas as espécies com padrão de fragmentação típico de hidrocarbonetos lineares. Em relação à composição qualitativa não foram identificadas diferenças entre as amostras dos indivíduos considerando espécies e sexo (Figuras 11 e 12; Tabela 3).

Ao comparar as quantidades totais dos compostos encontrados foi observado que os hidrocarbonetos não variam em quantidade entre machos e fêmeas nem entre as espécies analisadas $\left(\mathrm{F}_{3,15}=1,30 \mathrm{P}=0,31\right)$ (Figura 13). Da mesma maneira a analise multivariada não mostrou diferença significativa para a distribuição dos compostos entre espécie e sexo $\left(\mathrm{F}_{12,42}=1,58 \mathrm{P}=0,20\right)$, entretanto a representação gráfica da análise de variáveis canônicas mostrou uma clara separação entre os indivíduos por espécie e sexo. As primeiras duas variáveis canônicas explicam a maior parte da variabilidade observada $(95,7 \%)$ pelo que somente estas duas variáveis foram consideradas e representadas graficamente (Figura 14). A análise sugere que os extratos de fêmeas de C. ubica foram caracterizados pelos compostos tritiacontanto e nonadecano e os extratos de machos de $C$. ubica pelos compostos docosano e eicosano (Figura 13, Tabela 3). 
Tabela 3 Hidrocarbonetos identificados em amostras de fêmeas e machos $C$. ubica e C. impicticornis. Com seus respectivos tempos de retenção e quantidades representados. Quantidade média $(\mathrm{M} \pm \mathrm{DP})$, em ng/inseto, de cada amostra contendo 20 indivíduos. A identificação dos compostos foi obtida por análise em cromatógrafo gasoso (CG) acoplado a um espectrômetro de massas em coluna DB-5.

\begin{tabular}{|c|c|c|c|c|c|c|c|}
\hline \multirow{3}{*}{$\begin{array}{c}\mathrm{N}^{\circ} \\
\text { composto }\end{array}$} & & \multirow{3}{*}{ Hidrocarboneto } & \multirow{3}{*}{$\begin{array}{l}\text { Tempo de retenção } \\
\text { (min) }\end{array}$} & \multicolumn{4}{|c|}{ Quantidade (ng/inseto) } \\
\hline & & & & \multicolumn{2}{|c|}{ C.ubica } & \multicolumn{2}{|c|}{ C.impicticornis } \\
\hline & & & & q & $\hat{0}$ & $q$ & 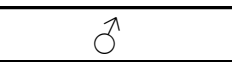 \\
\hline 1 & $n \mathrm{C} 19$ & Nonadecano & 31.77 & $0.009 \pm 0.009$ & $0.003 \pm 0.004$ & $0.006 \pm 0.005$ & $0.002 \pm 0.003$ \\
\hline 2 & $n \mathrm{C} 20$ & Eicosano & 33.56 & $0.088 \pm 0.155$ & $0.011 \pm 0.003$ & $0.011 \pm 0.009$ & $0.009 \pm 0.007$ \\
\hline 3 & $n \mathrm{C} 21$ & Heneicosano & 34.97 & $0.040 \pm 0.052$ & $0.010 \pm 0.010$ & $0.009 \pm 0.009$ & $0.007 \pm 0.004$ \\
\hline 4 & $n \mathrm{C} 22$ & Docosano & 36.18 & $0.058 \pm 0.067$ & $0.075 \pm 0.122$ & $0.021 \pm 0.016$ & $0.023 \pm 0.012$ \\
\hline 5 & $n \mathrm{C} 23$ & Tricosano & 37.24 & $0.145 \pm 0.197$ & $0.032 \pm 0.025$ & $0.032 \pm 0.026$ & $0.037 \pm 0.027$ \\
\hline 6 & $n \mathrm{C} 24$ & Tetracosano & 38.19 & $0.253 \pm 0.259$ & $0.124 \pm 0.122$ & $0.084 \pm 0.055$ & $0.114 \pm 0.112$ \\
\hline 7 & $n \mathrm{C} 25$ & Pentacosano & 39.08 & $0.426 \pm 0.455$ & $0.142 \pm 0.117$ & $0.117 \pm 0.105$ & $0.152 \pm 0.101$ \\
\hline 8 & $n \mathrm{C} 27$ & Heptacosano & 40.7 & $0.631 \pm 0.607$ & $0.214 \pm 0.230$ & $0.203 \pm 0.194$ & $0.264 \pm 0.181$ \\
\hline 9 & $n \mathrm{C} 28$ & Octacosano & 41.61 & $0.561 \pm 0.525$ & $0.240 \pm 0.182$ & $0.210 \pm 0.187$ & $0.255 \pm 0.169$ \\
\hline 10 & $n \mathrm{C} 29$ & Nonacosano & 42.68 & $0.543 \pm 0.483$ & $0.251 \pm 0.204$ & $0.281 \pm 0.228$ & $0.314 \pm 0.220$ \\
\hline 11 & $n \mathrm{C} 30$ & Triacontano & 43.96 & $0.362 \pm 0.320$ & $0.163 \pm 0.115$ & $0.174 \pm 0.157$ & $0.195 \pm 0.131$ \\
\hline 12 & $n \mathrm{C} 31$ & Hentriacontano & 45.49 & $0.397 \pm 0.321$ & $0.196 \pm 0.196$ & $0.222 \pm 0.178$ & $0.223 \pm 0.166$ \\
\hline 13 & $n \mathrm{C} 32$ & Dotriacontano & 47.39 & $0.151 \pm 0.138$ & $0.073 \pm 0.054$ & $0.069 \pm 0.074$ & $0.081 \pm 0.055$ \\
\hline 14 & $n \mathrm{C} 33$ & Tritriacontano & 49.72 & $0.182 \pm 0.221$ & $0.042 \pm 0.056$ & $0.049 \pm 0.046$ & $0.044 \pm 0.039$ \\
\hline
\end{tabular}




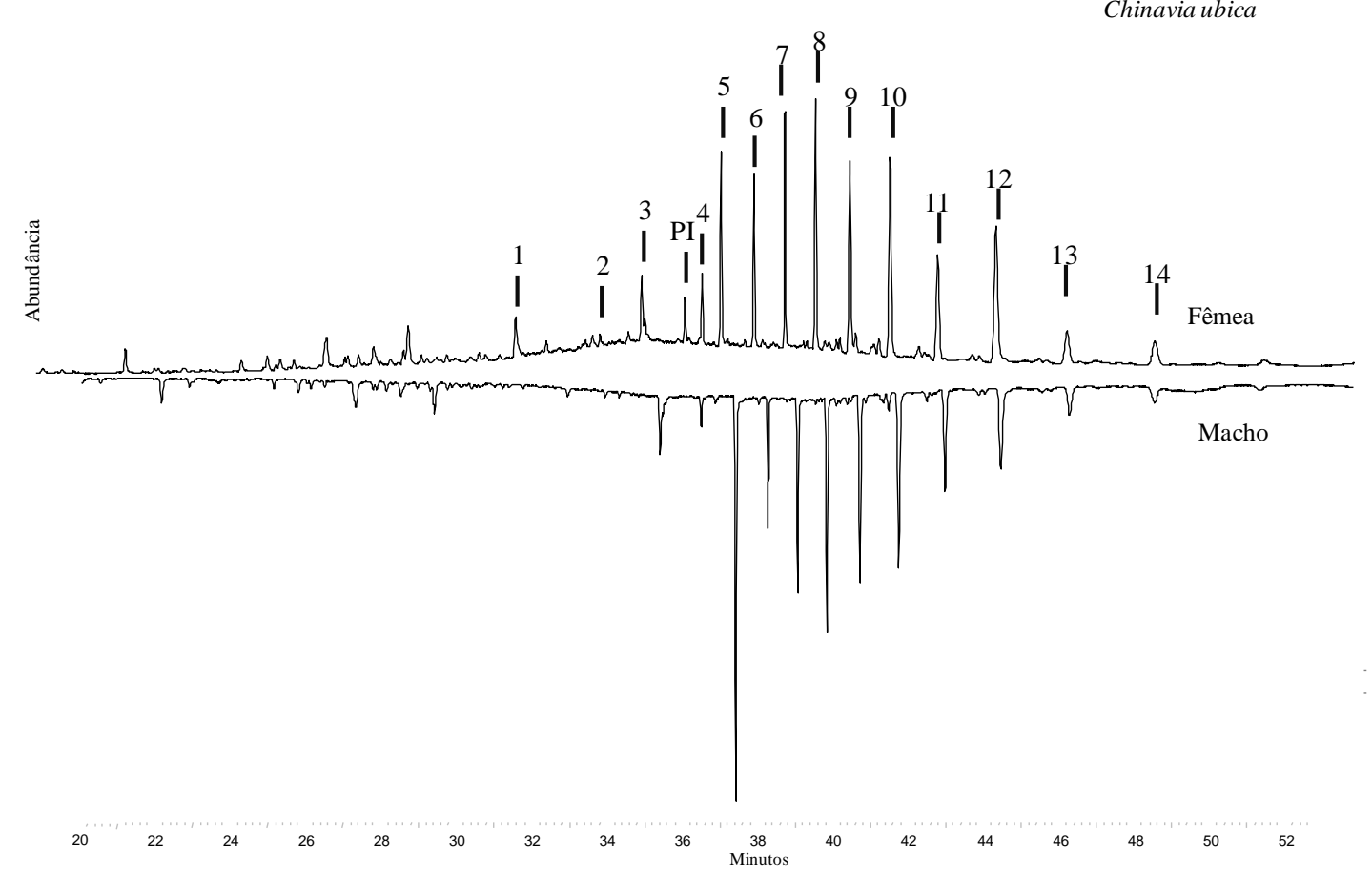

Figura 10: Cromatograma representativo obtido a partir de amostras de extratos cuticulares de 20 fêmeas e machos de C. ubica.

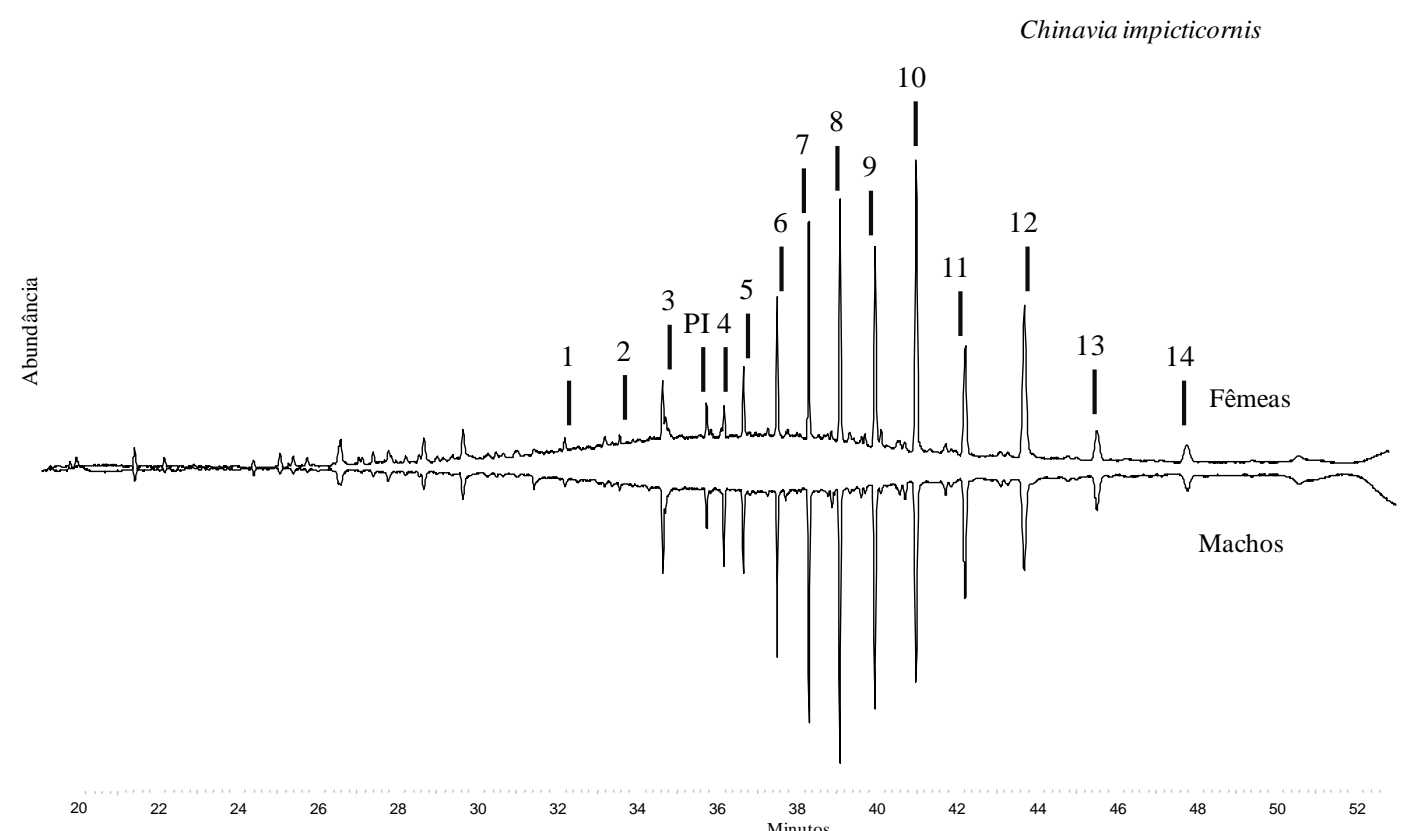

Figura 11: Cromatógrama representativo obtido a partir de amostras de extratos cuticulares de 20 fêmeas e machos de C. impicticornis. 


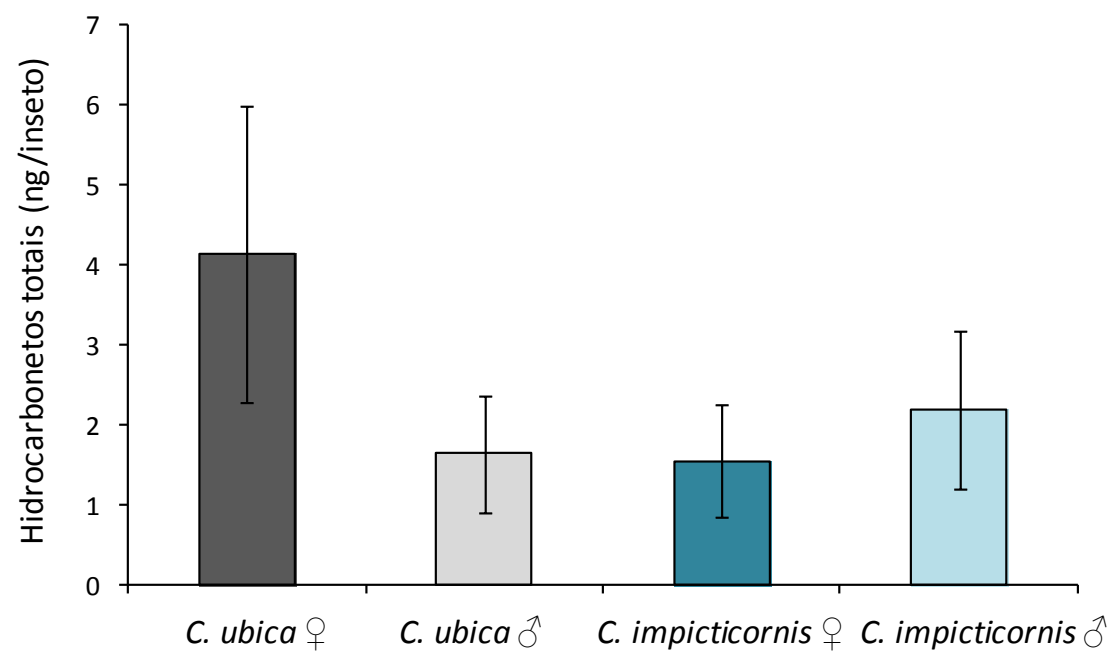

Figura 12: Quantidade total de hidrocarbonetos cuticulares em ng por inseto obtidas em amostras de pronoto e escutelo de fêmeas e machos C.ubica e C.impicticornis. As barras indicam o erro padrão.

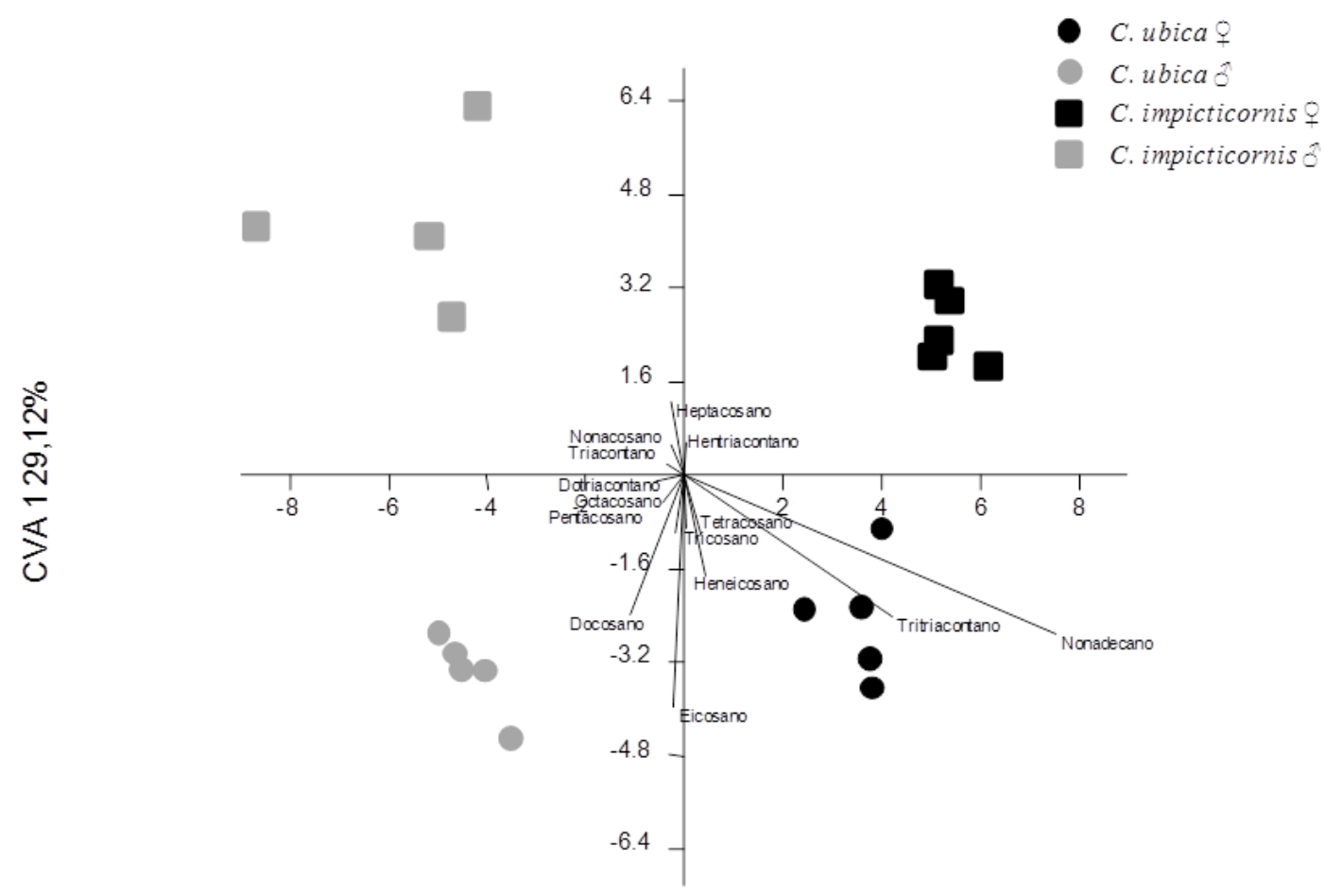

CVA $166,6 \%$

Figura 13: Análise de variáveis canônicas (CVA) considerando fêmeas e machos de $C$. ubica e $C$. impicticornis como fator e os hidrocarbonetos cuticulares identificados em amostras de ambas as espéciessexo. Os círculos representam os "scores" individuais para cada amostra (20 indivíduos de cada espécie e sexo) calculados a partir das equações da primeira e segunda variável canônica. As linhas representam as cargas ("loadings") para cada variável (composto) incluído na análise, a magnitude da linha representa a importância relativa de cada composto para diferenciar os tratamentos (espécie e sexo) nas duas dimensões do gráfico. 


\subsection{Discussão}

As análises de hidrocarbonetos encontrados em extratos cuticulares de $C$. ubica e C. impicticonis não mostraram diferenças qualitativas e quantitativas relevantes embora a análise de variáveis canônicas sugira que a composição de hidrocarbonetos cuticulares é diferente entre espécies e sexos com alguns compostos relacionados a cada espécie e sexo.

Os estudos da composição química da cutícula de percevejos ainda são escassos assim como a determinação de suas funções na comunicação entre os indivíduos. Os hidrocarbonetos identificados para as duas espécies de Chinavia são similares aos encontrados em Nezara viridula por Colazza et al. (2007), com exceção de hexacosano e tetratriacontano, que não foram encontrados nos extratos nas duas espécies analisadas neste trabalho. No caso de $N$. viridula a composição dos hidrocarbonetos cuticulares de machos diferencia-se das fêmeas pela ausência do composto nonacosano. Adicionalmente estratos das fêmeas desta espécie possuem quantidades maiores de tricosano, tetracosano e pentacosano e os (Colazza et al., 2007). Assim o composto nonadecano parece estar ligado à sinalização do sexo (neste caso as fêmeas) nesta espécie. Os hidrocarbonetos cuticulares presentes nos rastros de $N$. viridula podem ser utilizados pelo parasitoide Trissolcus basalis (Wollaston) como rastros químicos durante a procura de hospedeiros (Colazza et al., 2007, De Pasquale et al., 2007). COLAZZA et al., (2007) mostraram que o composto nonadecano é utilizado pelo inimigo natural, Trissolcus basalis, como pista na procura pelo hospedeiro, discriminando com base neste hidrocarboneto rastros de macho e fêmeas. A utilização de rastros químicos, constituídos principalmente de hidrocarbonetos cuticulares, pelos inimigos naturais de percevejos tinha sido previamente demonstrada para o parasitoide Telenomus podisi (Ashmed) (Borges et al. 2003). Em Bagrada hilaris (Burmeister) (Heteroptera: Pentatomidade) também foram registrados hidrocarbonetos lineares n-alcanos.

Além disso, as duas espécies de Chinavia estudadas possuem ainda triacontano, hentriacontano, octacosano e tritriacontano, que não foram encontrados em Bagrada hilaris, além disso, as fêmeas dessa espécie possuem quantidades maiores em todos os compostos identificados na cutícula da espécie (De Pasquale et al., 2007). Também foram encontrados hidrocarbonetos de cadeia linear em Dichelops melacanthus e Euchistus heros (Rossi et al., 2015).

Estes compostos foram identificados também como componentes do feromônio sexual de outra espécie filogeneticamente relacionada, Nezara viridula, (Baker et al., 
1987). Isto sugere um mecanismo similar de diferenciação tanto para os feromônios sexuais quanto para os hidrocarbonetos cuticulares, onde especificidade na comunicação química é garantida por diferentes combinações e proporções dos compostos nas misturas.

Além da emissão de feromônios (utilizados a longas distâncias), quando os insetos se encontram na mesma planta os percevejos se comunicam utilizando sinais vibratórios (Čokl et al., 2008). Estes sinais também mostram diferencias entre espécies e sexos que contribuem para a especificidade da comunicação (Laumann. A.R., BlassioliMoraes, M.C., Borges, M., dados não publicados), o que foi demonstrado nos experimentos do Capítulo 1 desta dissertação.

Assim as diferentes modalidades de sinais utilizadas na comunicação a longas distâncias (feromônios), a distâncias moderadas, quando os insetos se encontram na mesma planta (sinais vibratórios), e a curta distância, quando os insetos estão em contato físico (hidrocarbonetos cuticulares), podem contribuir decisivamente para reconhecimento entre os indivíduos e garantem o isolamento reprodutivo nas espécies de Chinavia estudadas.

Hidrocarbonetos lineares também são comuns em outros grupos de insetos como em Blatella germanica (Linnaeus, 1767) (Rivalt et al., 2002). Alguns desses hidrocarbonetos lineares, como heneicosano, docosano, tricosano, tetracosano, pentacosano, octacosano, nonacosano, triacontano, hentriacontano e dotriacontano também são encontrados nos rastros de lagartas de Spodoptera frugiperda (Smith \& Abbot, 1797), que são utilizados como cairomônios pelo parasitoide Cotesia marginiventris (Cresson), induzindo o comportamento de antenação (Rostás \& Wölfling, 2009; Wölfling \& Rostás, 2009). Tricosano, pentacosano, heptacosano, octacosano, nonacosano, triacontano, hentriacontano, tritriacontano foram identificados nos extratos cuticulares em Sitobion avenae (Fabricius) (Hemiptera: Aphididae) (Muratori et al., 2008).

Hidrocarbonetos cuticulares podem ser utilizados também por parasitas para mimetizar a cutícula dos seus hospedeiros como no caso de Thorictus martinezi (Escalera, 1923) um coleóptero parasita obrigatório de ninhos formigas, este inseto possui um perfil de hidrocarbonetos cuticulares idêntico ao das formigas que parasita o que impede ser reconhecido como invasor nas colônias (Lenoir et al., 2013). 
Embora os alcanos sejam os lipídios cuticulares mais dominantes, eles variam em número e quantidade dependendo da espécie em questão (Frere et al., 2014). O papel dos hidrocarbonetos cuticulares como feromônio de contato induzindo o comportamento de corte em distâncias curtas tem sido descrito em Coleoptera (Ginzel et al., 2003; OrtizDomínguez et al., 2006), Diptera (Carlson et al., 1984; Uebel et al., 1975 in Paquale et al., 2007) e Hymenoptera (Howard \& Baker, 2003). Esses hidrocarbonetos exercem frequentemente o papel de reconhecimento de possível parceiro para cópula (Ishii et al., 2002).

Os resultados obtidos indicam uma possível diferenciação da composição química da cutícula entre espécie e sexo das espécies de Chinavia estudadas. Para comprovar a relevância dos hidrocarbonetos cuticulares no reconhecimento interesepecífico e entre indivíduos (machos e fêmeas) é necessário avaliar a influência dos mesmos no comportamento reprodutivo dos insetos. 


\section{Considerações finais}

No presente trabalho foi estudada a resposta de machos de duas espécies de pentatomídeos, C. ubica e C. impicticornis, às alterações nos cantos naturais de fêmeas coespecíficas, além de uma análise da composição química da cutícula. Como o esperado, C. ubica e C. impicticornis são capazes de distinguir e responder seletivamente aos sinais das fêmeas coespecíficas e possuem diferenças na composição dos hidrocarbonetos cuticulares que podem estar relacionadas com o reconhecimento e discriminação de parceiros durante o comportamento reprodutivo. Estas respostas seletivas estariam relacionadas com o isolamento reprodutivo dessas espécies simpátricas. Trabalhos futuros devem ser orientados a fim de estabelecer a especificidade das respostas das fêmeas aos sinais dos machos e a função biológica específica de cada tipo de sinal. Para refinar os resultados acerca da relevância dos hidrocarbonetos cuticulares um estudo mais aprofundado deve considerar uma maior amostragem, análise mais detalhada dos componentes minoritários e estudos biológicos e comportamentais que coloquem em evidência a importância destes compostos como sinais químicos de curta distância e sua influência no comportamento reprodutivo dos insetos. 


\section{Referências Bibliográficas}

BAGNÈRES, A.G., LORENZI, M.C., DUSTICIER,G., TURILLAZZI, S., CLÉMENT, J.L. (1996). Chemical usurpation of a nest by paper wasp parasites. Science 272:889-92.

BAKER, R., BORGES, M., COOKE, N. G., HEBERT, H. R. (1987). Identification and synthesis of (Z)-1'S,3'R,4'S)(-)-2-(3',4'-Epoxy-4'-Methylcyclohexyl)-6-Methylhepta-2-5Diene, the sex pheromone of the southern green stingbug, Nezara viridula (L.). Journal of the Chemical Society, Chemical Communications, v. 6, n.6, p. 414-416.

BELORTE L.C., RAMIRO, Z.A., FARIA, A.M,. MARINO, C.A.B (2003). Danos causados por percevejos (Hemiptera: pentatomidae) em cinco cultivares de soja (Glycine $\max ($ L.) Merril, 1917) no município de Araçatuba, SP. Arq Inst Biol, São Paulo 70: 169175.

BERGMANN, J., GONZÁleS, A., ZARBIN, P.H.G. (2009). Insect Pheromone Research in South America. Journalof the Brazilian Chemical Society. Vol. 20, No. 7, 1206-1219.

BLASSIOLI-MORAES, LAUMANN, R.A., OLIVEIRA, M.W.M., WOODCOCK, C.M., MAYON, P., HOOPER, A., PICKETT, J.A., BIRKETT, M.A., BORGES, M. (2012). Sex Pheromone Communication in Two Sympatric Neotropical Stink Bug Species Chinavia ubica and Chinavia impicticornis. Journal of Chemical Ecology. 38:836-845.

BLASSIOLI-MORAES, M.C., MAGALHÃES, D.M.M., ČOKL, A., LAUMANN, R.A., SILVA, J.P., SILA, C.C.A., BORGES, M. (2013). Vibrational communication and mating behaviour of Dichelops melacanthus (Hemiptera: Pentatomidae) recorded from loudspeaker membranes and plants. Physiological Entomology. 39, 1-11.

BLOMQUIST, G.J., BAGNÈRES, A.G. (2010). Insect Hydrocarbons. Cambridge University Press, New York. Pp 3. 19-34.

BORGES, M., JEPSON, P.C., HOWSE, P.E. (1987). Long-range mate location and close-range courtship behaviour of the Green Stink Bug, Nezara viridula and its mediation by sex pheromones. Entomologia experimentalis et applicata. 44: 205-212.

BORGES, M., SCHMIDT, F.V.G, SUJII, E.R., MEDEIROS, M.A, MORI, K., ZARBIN, P.H., FERREIRA, J.T.B.(1998a) Field responses of stink bugs to the natural and synthetic pheromone of the neotropical brown stink Bug, Euschistus heros, (Heteroptera: Pentatomidae). Physiological Entomology. v. 23, p. 202-207.

BORGES, M., MORI, K., COSTA, M. L. M., SUJII, E.R. (1998). Behavioural evidence of methyl-2,6,10-trimethyltridecanoate as a sex Pheromone of Euschistus heros (Heteroptera: Pentatomidae). Journal of Applied Entomology. v. 122, n. 6, p. 335-338.

BORGE S, M., COLAZZA, S., R A M I R E Z - L U C A S,. P., CHAUHAN, K., MORAES, M.C.B., ALDRICH, J.R. (2003). Kairomonal effect of walking traces from Euschistus heros (Heteroptera: Pentatomidae) on two strains of Telenomus podisi (Hymenoptera: Scelionidae). Physiological Entomology. 28, 349-355. 
BORGES, M., BIRKETT, M., ALDRICH, J.R., OLIVER, J.E., CHIBA, M., LAUMANN, R.A., BARRIGOSSI, J.A., PICKETT, J.A., MORAES, M.C.B. (2006). Sex Attractant Pheromone from the Rice Stalk Stink Bug, Tibraca limbativentris Stal. Journal of Chemical Ecology. 32:2749-2761.

BORGES, M., MILLAR, J.G., LAUMANN, R.A., MORAES, M.C.B. (2007). A Maleproduced Sex Pheromone from the Neotropical Redbanded Stink Bug, Piezodorus guildinii (W.). Journal of Chemical Ecology. 33:1235-1248.

BORGES, M. ; MORAES, M.C.B.,; Peixoto, M.F.,; PIRES, C.,; SUJII, E. R., LAUMANN, R.A. (2011). Monitoring the neotropical brown stink bug Euschistus heros (F.) (Hemiptera: Pentatomidae) with pheromone-baited traps in soybean fields. Journal of Applied Entomology (1986), v. 135, p. 68-80.

BRAGA, M.V., PINTO, Z.T., QUEIROZ, M.M.C., MATSUMOTO, N., BLOMQUIST, G.J. (2013). Cuticular hydrocarbons as a tool for the identification of insectspecies: Puparial cases from Sarcophagida. Acta Topica. vibrational communication. Bioscience, 55, 323-334.

CARLSON, D.A., NELSON, D.R., LANGLEY, P.A., COATES, T.W., DAVIS, T.L., LEEGWATER, V.L.M. (1984). Contact Sex Pheromone in the Tsese Flies Glossinia pallidipes Austen: identification and synthesis. Journal of Chemical Ecology. 19: 429450 .

COCROFT, R. B., RODRÍGUES, R. L. (2005). The behavioural ecology of insect

COCROFT, R.B. (2011). The public world of insect vibrational communication. Molecular Ecology. 20, 2041-2043.

COlAZZA, S., AQUILA, G., De PASQUALE, C., PERI, E., MILlAR, J.G.(2007). The Egg Parasitoid Trissolcus basalis uses n-nonadecane, a Cuticular Hydrocarbon from its Stink Bug Host Nezara viridula, to Discriminate Between Female and Male Hosts. Journal of Chemical Ecology. 33:1405-1420.

ČOKL, A, GOGALA M, BLAZEVIC, A. (1978) Principles of sound recognition in three Pentatomidae bug species (Heteroptera). Bioloski vestnik 26:81-94.

ČOKL, A., VIRANT-DOBERLET, M., STRITIH, N. (2000a). Temporal and spectral properties of the songs of the southern green stink bug Nezara viridula (L.) from Slovenia. Pflugers Arch - Eur J Physiol. 439: R168-R170.

ČOKL, A., VIRANT-DOBERLET, M., STRITIH, N. (2000b). The structure and function of songs emitted by southern green stink bugs from Brazil, Florida, Italy and Slovenia. Physiological Entomology, 25, 196-205.

ČOKL, A., McBRIEN, H.L., MILLAR, J.G. (2001). Comparison of Substrate-Borne Vibrational Signals ofTwo Stink Bug Species, Acrosternum hilare and Nezara viridula (Heteroptera: Pentatomidae). 94(3):471-479.

ČOKL, A., VIRANT-DOBERLET, M. (2003). Communication with substrate-borne signals in small plant-dwelling insects. Annual Review Entomology. 48:29-50. 
COCROFT, R. B., RODRÍGUES, R. L. (2005). The behavioural ecology of insect vibrational communication. Bioscience, 55, 323-334.

ČOKL, A. (2008). Stink Bug interaction with host plants during communication. Journal of Insect Physiology. 54, 1113-1124.

ČOKL, A., MILLAR, J.G. (2009). Manipulation of Insect Signaling for Monitoring and Control of Pest Insects Biorational Control of Arthropod Pests. pp 279-316.

CORREAA-FERREIRA, B.S.; PANIZZI, A.R. (1999). Percevejos da soja e seu manejo. (Circular técnica, 24). Londrina: Embrapa-CNPSo, 45p.

CONAB - Companhia Nacional de Abastecimento.(2015). Primeiro Levantamento Outubro/2013 V.2 - SAFRA 2014/15 N.4 - Quarto Levantamento Janeiro/2015 Monitoramento Agrícola Cultivos de Verão - SAFRA 2014/15.

De Pasquale, C., GUARINO, S., PERI, E., AlOnZO, G., COlAZZA, S. (2007). Investigation of cuticular hydrocarbons from Bagrada hilaris genders by SPME/GC-MS C. Anal Bioanal Chem. 389:1259-1265.

DIETEMANN, V., PEETERS, C., LIEBIG, J., THIVET, V. (2003). Cuticular hydrocarbons mediate discrimination of reproductives and nonreproductives in the ant Myrmecia gulosa. PNAS. 10341-10346.

EBERHARD, M.J.B., PICKER, M.,D. (2008). Vibrational Communication in Two Sympatric Species of Mantophasmatodea (Heelwalkers). 21:240-257.

FÁVARO, C.F., ZARBIN, P.H.G. (2012). Identificação dos Compostos Defensivos Encontrados nas Glândulas Metatorácica e Abdominais Dorsais dos Percevejos Loxa deducta E Pellaea stictica (Heteroptera: Pentatomidae). Quimica Nova, (35) 8: 15821586.

FERREIRA,C.R.R.P.T., CAMARGO, M.L.B., VEGRO, C.L.R. (2012). Defensivos Agrícolas: comercialização recorde em 2011 e expectativas de acréscimo nas vendas em 2012. Análises e Indicadores do Agronegócio. v. 7, n. 7. 2012.

FRERE, B., SUCHAUD, F., BERNIER, G., COTTIN, F., VINCENT, B., DOUREL, L., LELONG, A.\&ARPINO, P. 2014. GC-MS analysis of cuticular lipids in recent and older scavenger insect puparia. An approach to estimate the postmortem interval (PMI). Analytical and Bioanalytical Chemistry 406: 1081-1088.

GEMENO, C., LASERNAL, N., RIBA, M., VALls, J., CASTAÑE, C., ALOMAR, O. (2012). Cuticular hydrocarbons discriminate cryptic Macrolophus species (Hemiptera: Miridae). Bulletin of Entomological Research. 6(102): 624-631.

GINZEL, M.D., BLOMQUIST, G.J., MILLAR, J.G., HANKS, L.M. (2003). Role of Contact Pheromones in Mate Recognition in Xylotrechus colonus. Journal of Chemical Ecology. 3(29): 533-545.

GREENFIELD, M.D. (2002). Signals and receivers. Mechanism and evolution of arthropod communication. Oxford University Press. New York. 414 pp. 
de GROOT, M., ČOKL, A., VIRANT-DOBERLET, M. (2011). Species identity cues: possibilities for errors during vibrational communication on plant stems. Behavioral Ecology.

HILL, P.S.M. (2009). How do animals use substrate-borne vibrations as an information source? Naturwissenschaften. 96:1355-1371.

HILL, P.S.M. (2008) Vibrational Communication in Animals. Havard University Press. Cambridge, Massachusetts. London, England.

HOWARD, R.W., McDANIEL, C.A., NELSON, D.R., BLOMQUIST, G.J., GELBAUM, L.T., ZALKOW, L.H. (1982). Cuticular Hydrocarbons of Reticulitermes virginicus (Banks) and Their Role as Potential Species and Caste Recognition Cues. Journal of Chemical Ecology, Vol. 8, No. 9.

HOWARD, RW, LIANG, Y. (1993). Cuticular hydrocarbons of winged and wingless morphs of the ectoparasitoid Choetospila elegans Westwood (Hymenoptera: Pteromalidae) and its host, larval lesser grain borer (Rhyzopertha dominica) (Coleoptera: Bostrichidae). Comparative Biochemistry and Physiology. 106B:407-14.

HOWARD, R.W. BAKER, J.E. (2003). Cuticular hydrocarbons and wax esters of the ectoparasitoid Habrobracon hebetor: ontogenetic, reproductive and nutritional effects. Archives of Insect Biochemistry and Physiology. 53: 1-18.

HOWARD, R.W., BLOMQUIST, G.J. (2005). Ecological, Behavioral and Biochemical Aspects of Insects Hydrocarbons. Annu. Rev. Entomol. 2005. 50:371-93.

HRABAR, N., VIRANT-DOBERLET, M, ČOKL, A. (2004). Species specificity of male southern green stink bug Nezara viridula (L.) reactions to the female calling song. Acta Zoolog Sin. 50:566-575.

ISHII, K., HIRAI, Y., KATAGIRI, C., KIMURA, M.T. (2002) Mate discrimination and cuticular hydrocarbons in Drosophila elegans and D. gunungcola. Zoological Science, 19, 1191-1196.

JACKSON, L.L. (1983). Cuticula Hydrocarbons of the Milkweed Bug Ontopelcus fasciatus by Age and Sex. Insect Biochemistry., 13: 19-25.

JALLON, J.M., DAVID, J.R. (1987). Variations in Cuticular Hydrocarbons Among the Eight Species of the Drosophila melanogaster Subgroup. Evolution, 41(2), 1987, pp. 294302.

JURENKA, R.A., MITKO, S. Identification of Cuticular Hydrocarbons and the Alkene Precursor to the Pheromone in Hemolymph of the Female Gypsy Moth, Lymantria díspar. (2000). Archives of Insect Biochemistry and Physiology. 43(3):108-15.

KON, M., OE, A., NUMATA, H., HIDAKA, T. (1988). Comparison of the mating behaviour between two sympatric species, Nezara antennata and N. viridula (Heteroptera: Pentatomidae), with special reference to sound emission. Journal of Ethology. 6:91-98. 
LAUMANN, R. A., MORAES, M.C.B., KHRIMIAN, A., BORGES, M. (2011). Field capture of Thyanta perditor with pheromone-baited traps. Pesquisa Agropecuária Brasileira. v. 46, p. 113-119.

LAUMANN, R.A., KAVICIC, A., MORAES, M.C.B., BORGES, M., ČOKL, A. Reproductive behaviour and vibratory Communication of the neotropical predatory stink bug Podisus nigrispinus. Physiological Entomology. 38, 71-80. 2013.

LENOIR, A., HÁVA, J., HEFETZ, A., DAHBI, A., CERDÁ, X., BOULAY, R. (2013). Chemical integration of Thorictus myrmecophilous beetles into Cataglyphis ant nests Systematics and Ecology. 51: 335-342.

LOCKEY, K.H. (1988). Lipids of the Insect Cuticle: Origin, Composition and Fuction. Comparative Biochemistry and Physiology. Vol. 89B, No. 4, pp. 595-645.

LOPES, A P., LAUMANN, R. A., MOTTA, L.S.M., MORAES, M.C.B., BORGES, M. (2006). Comportamento reprodutivo e comunicação vibracional de Chinavia ubica $e$ Chinavia impicticornis. In: XXI Congresso Brasileiro de Entomologia, 2006, Recife - Pe.

LUCAS, C., FRESNEAUS, D., JALLON, J.M. (2004). Hydrocarbon circulation and colonial signature in Pachycondyla villosa. Journal of Insect Physiology. 50 (2004) 595607.

MICHELSEN, A., FINK, F., GOGALA, M., TRAUE, D. (1982). Plants as transmission channels for insect vibrational songs. Behavioral Ecology and Sociobiology. 11:269-281.

MIKLAS, N., STRITIH, N., ČOKL, A., VIRANT-DOBERLET, M., RENOU, M. The influence of substrate on male responsiveness to the female calling song in Nezara viridula. Journal of Insect Behavior. Vol. 14, No. 3, 2001.

MORAES, M.C.B., MILlAR, J.G., LAUMANN, R.A., SUJII, E.R., PIRES, C.S.S., BORGES. M. (2005) Sex Attractant Pheromone From The Neotropical Red - Shouldered Stink Bug, Thyanta perditor (F.). Journal of Chemical Ecology, Vol. 31, No. 6.

MORAES, M.C.B., PEREJA, M., LAUMANN, R.A., BORGES, M. (2008). The chemical volatiles (Semiochemicals) produced by neotropical stink bugs (Hemiptera: Pentatomidae). Neotropical Entomology. 37(5):489-505.

McBRIEN, H.L., MILLA, J.G. (1999). Pheromones of phytophagous true bugs. Chapter 11. In: pheromones of nonlepidopteran insect pests of agriculture. Ed. by Minks Ak, Hardie J. CAB International, Wallingford, England, pp. 277-304.

McGREGOR, P.K. (2005) Communication. In: Bolhuis JJ, Giraldeau LA (eds) The behaviour of animals. Mechanisms, function, and evolution. Blackwell, Oxford, pp 226251.

MILlAR, J. G., McBRIEN, H. L., HO, H. -Y, RICE, R. E., CULLEN.E., ZALOM, F. G., and UOKL, A. (2002). Pentatomid bug pheromone in IPM: Possible applications and limitations. IOBC wprs Bulletin. V. 25, p. 1-11. 
MURATORI, F., HANCE, T., LOGNAY, G. (2008). Chemical Characterization of Cuticular Extracts of Sitobion avenae (Hemiptera: Aphididae). Annals of the Entomological Society of America. 101(3): 598-603.

NELSON, D.R., CARLSON, D.A., FATLAND, C.L. (1986). Cuticula Hydrocarbons of the Tsetse Flies Glossina morsitans morsitans. Journal of Chemical Ecology, Vol. 14, No. 3.

ORTIZ-DOMINGUEZ, M., FAMILA, M.E., MEDONZA-LOPEZ, M.R., GARCIABARRADAS, O., CRUZ-SANCHES, J.S. (2006). Epicuticular compounds and Sexual Recognition in the Ball-rolles scarab, Canthon cyanellus cyanellus. Entomologia Experimentalis et Applicata. 119: 23-27.

PANIZZI, A.R. (1997) Wild hosts of pentatomids: ecological significance and role in their pest status crops. Annual Review of Entomology. v.42, p.99-122.

PANIZZI, A.R., VIVAN, A.M. (1997). Seasonal abundance of the neotropical brown stink bug, Euschistus heros, in overwintering sites, and the breaking of dormancy. Entomologia Experimentalis et Applicata 82: 213-217.

PANIZZI, A. R. \& SCHAEFER, C.W. (2000). Heteroptera of Economic Importance. CRC Press, Boca Raton London, New York Washington. Pp 421.

PANIZZI, A.R., BUENO, A.F., SILVA, F.A.C. Soja - Manejo Integrado de Insetos e Outros Artrópodes Praga. (2013). Editora Embrapa. Pag. 370. 2013.

PEETERS, C., MONNIN, T., MALOSE, C. (1999). Cuticular hydrocarbons correlated with reproductive status in a queenless ant. Proceeding of The Royal Society. 266

PERCY, D.E.A.B., HODDLE, M.S. (2008). Observations of Acoustic Signaling in Three Sharpshooters: Homalodisca vitripennis, Homalodisca liturata, and Graphocephala atropunctata (Hemiptera: Cicadellidae). Annals of the Entomological Society of America. 101(1): 253-259.

PIRES, C.S.S. , SUJII, E.R , SCHMIDT, F. G. V., ZARBIN, P. H. G. , ALMEIDA, J. R. M., BORGES, M. (2006). Potencial de uso de armadilhas iscadas com o feromônio sexual do percevejo marrom, Euschistus heros (Heteroptera: Pentatomidae), para o monitoramento populacional de percevejos praga da soja. Manejo Integrado de Plagas y Agroecología. v. 7, p. 70-77.

RIVAUlT, C., ClOAREC, A., SRENG, L. (2002). Are Differences in Hydrocarbons Profiles Able to Mediate Strain Recognition in German cockroaches (Dictyoptera: Blattellidae)? European Journal of Entomology. 99: 437-444.

RODRÍGUES-LOECHES, L., BARRO, A., PÉREZ, M., CORO, F. (2009). Anatomic and acoustic sexual dimorphism in the sound emission system of Phoenicoprocta capistrata (Lepidoptera: Arctiidae). Naturwissenschaften.

ROSSI, M.B., BLASSIOLI-MORAES, M.C., LAUMANN, R.A., Borges, M. Identificação dos Hidrocarbonetos Cuticulares de Dichelops melacanthus (HEMIPTERA: 
PENTATOMIDAE) e Euschistus heros (HEMIPTERA: PENTATOMIDAE). Talento estudantil, Embrapa, 2015.

SCHWERTNER, C.F., GRAZIA, J. (2006). Descrição de seis espécies de Chinavia (Hemiptera, Pentatomidae, Pentatominae) da América do Sul. Iheringia, Série Zoologia, 96(2):237-248.

SCHWERTNER, C.F., GRAZIA, J. (2007). O gênero Chinavia Orian (Hemiptera, Pentatomidae, Pentatominae) no Brasil, com chave pictórica para os adultos. Revista Brasileira de Entomologia 51(4): 416-435.

SCOTT-PHILIPS, T.C. (2008). Defining biological communication. Journal of Evolutionary Biology. 21: 387-395.

SILVA, C.C.A., LAUMANN, R.A., BLASSIOLI-MORAES, M.C., AQUINO, M.F.S., BORGES, M. (2015). Comparative biology of two congeneric stinkbugs, Chinavia impicticornis and C. ubica (Hemiptera: Pentatomidae). Pesq. agropec. bras., Brasília, v.50, n.5, p.355-362.

STOFFOLANO, J.G., SCHAUBER, E., YIN, C.M., TILLMAN, BLOMQUIST, G.J. (1997). Cuticular Hydrocarbons and their Role in Copulatory Behavior in Phormia Regina (Meigen). J. Insect Physiol. Vol. 43, No. 11, pp. 1065-1076.

SUEUR, J., AUBIN, T. (2006). When males whistle at females: complex FM acoustic signals in cockroaches. Naturwissenschaften. 93:500-505.

SUEUR, J., AUBIN, T. (2004). Acoustic signals in cicada courtship. The Zoological Society of London. 262, 217-224.

UEBEL, E.C., SONNET,P.E., MILLER, R.W., BEROZA, M. (1975) Journal of Chemical Ecology 1:195-202.

VIRANT-DOBERLET, M., ČOKL, A. (2004). Vibrational communication in insects. Neotropical Entomology v. 33, n.2, p. 121-134.

WILGENBURG, E., FELDEN, A., CHOE, D.H., SUlC, R., LUO, J., SHEA, K.J., ELGAR, M.A., TSUSUI, N. (2013). Learning and discrimination of cuticular hydrocarbons in a social insect. Biology Letters. Published online.

ZARBIN, P.H.G., BORGES, M., dos SANTOS, A.A., OLIVEIRA, A.R.M., SIMONELliA, F., MARQUES, F. (2000). Alarm Pheromone System of Stink Bug Piezodorus guildinii (Heteroptera: Pentatomidae) Journal of the Brazilian Chemical Society. Vol. 11, No. 4, 424-428.

ZARBIN, P.H.G., FÁVARO, C.F., VIDAL, D.M., RODRIGUES, M.A.C.M. (2012). Male-Produced Sex Pheromone of the Stink Bug Edessa meditabunda. Journal of Chemical Ecology.. 38:825-835.

ZHANG, A., BORGES, M., ALDRICH, J.R., CAMP, M. (2003). Stimulatory MaleVolatiles for the Neotropical Brown Stink Bug, Euschistus heros (F.) (Heteroptera: Pentatomidae). Neotropical Entomology 32(4):713-717. 
ŽUNIC, A., VIRANT-DOBERLET, M., ČOKL, A. (2011). Species recognition during Ssbstrate-borne Ccmmunication in Nezara viridula (L.) (Pentatomidae: Heteroptera). Journal Insect Behaviour. 24:468-487. 